\title{
New Theoretical Perspectives on the Distribution of Income and Wealth Among Individuals
}

Joseph E. Stiglitz ${ }^{1}$

Columbia University

\subsection{New stylized facts of growth and distribution}

A central question of economics has been: how do we explain the distribution of income among factors of production, and the distribution of income and wealth among individuals.

Some fifty years ago, theorists tried to develop explanations for what were then viewed to be the stylized facts of growth and distribution, articulated, for instance, by Nicholas Kaldor. ${ }^{2}$ Among the central facts was the constancy of the capital-output ratio and the relative shares.

Today, there seems to be a new set of stylized facts that have to be explained, many of them markedly different from those that were the center of attention a half century ago. ${ }^{3}$ Among the empirical observations are the following (some of these "facts" are truer for some countries than others; and there are a few country exceptions): ${ }^{4}$

(a) Growing inequality in both wages and capital income (wealth), and growing inequality overall. ${ }^{5}$

(b) Wealth is more unequally distributed than wages.

(c) Average wages have stagnated, even as productivity has increased, so the share of capital has increased. ${ }^{6}$

(d) Significant increases in the wealth-income ratio. ${ }^{7}$

(e) The return to capital has not declined, even as wealth-income ratio has increased.

The new stylized facts put a new light on Kuznets' hypothesis ${ }^{8}$ that, while in earlier stages of development, inequality would grow, eventually inequality would fall. While that may have been true in the golden age of capitalism, between the end of World War II and around 1980, the period in which Kuznets was writing, such a conclusion no longer seems warranted. 
In particular, Piketty (2014) has presented data showing that the decades following World War II were an historical anomaly, the one period in which capitalism was not characterized by a high level of inequality. He argues that not only has there been a large increase in inequality since 1980, but that the wealth of the economy, largely held by those at the top, will continue to grow faster than the overall economy. ${ }^{9}$ If capitalists save all of their income, their wealth will grow at the rate of return, $r$, and if, as he hypothesizes, that is persistently above the rate of growth of the economy, $g$, their wealth relative to national income will grow at the rate of $r-g$.

Anecdotes aren't proofs, but they sometimes can alert us to factors that might have escaped attention in a simple model. John D. Rockefeller was America's first billionaire. At death, in 1937, his assets amounted to 1.5 percent of GDP. Had his assets grown at the rate " $g$ " (the rate of growth of the economy) they would be worth today some $\$ 340$ billion. If $r$ (the relevant rate of return) were just 1 percent more than $g$, their family wealth should have grown to $\$ 680$ billion. If, using numbers that Piketty might say are still conservative, but more realistic, the disparity between $g$ and $r$ is 2 percent, then their wealth would have been $\$ 1.3$ trillion. Instead, the total value of the family assets is estimated to be $\$ 10$ billion - less than 1 percent of the predicted amount - divided among almost 300 members. ${ }^{10}$

\section{A critique}

Three criticisms are raised against the Piketty analysis. First, once it is recognized that even capitalists consume, and that workers save out of wages (for life-cycle savings), then the neat relationship posited by Piketty for the ever-increasing capital-income ratio and inequality breaks down. For the wealth-income ratio of capitalists to be ever increasing would require sr $>$ g, but in standard Solow model of growth, where workers save at the same rate that capitalists do, that inequality does not hold in the long run.

Secondly, the return to capital should be treated as endogenous. If the increase in wealth represented an increase in "capital," then the law of diminishing returns would imply that the return to capital should have decreased. Once account is taken of the endogeneity of $r$, a more subtle analysis of the determinants of wealth inequality is required. Indeed, even the central policy proposal, a (global) capital tax may not have the desired effect if there is tax shifting.

\section{The disparity between $W$ and $K$ and the growth}

\section{in land and other rents.}

Thirdly, and most importantly, while both wealth and capital are aggregates, they are distinctly different concepts. Once one recognizes this, it becomes easy to reconcile the stylized facts with conventional theory. The wealth-income ratio could be increasing even as the capital-income ratio (appropriately measured) is stagnating or decreasing. Much of wealth is not produced assets 
("machines") but land ${ }^{11}$ or other ownership claims giving rise to rents. ${ }^{12}$ Some of the increase in wealth is the increase in the capitalized value of what might be called exploitation rents - associated with monopoly rents and rents arising from other deviations from the standard competitive paradigm. Some is an increase in the value of rents associated with intellectual property.

But that forces the analysis back one step: how do we explain the increase in the magnitudes of rents and the value of these assets? And what is the relationship between the increase in the value of these assets and the increase in inequality?

An analysis of the forces giving rise to the increase in land values and exploitation rents provides some insights into why there has been such a marked increase in wealth (and income) inequality, enables us to assess whether such increases are likely to continue, and to identify policies that might militate against these increases. If these assets are disproportionately owned by the rich, policies that lead to an increase in the value of these assets could have a first-order effect in increasing wealth inequality. We suggest that tax and financial market policies may have had these effects, and thus may have played an important role in the creation of today's high levels of inequality. ${ }^{13}$

\section{Explaining the stylized facts}

Solow, Kaldor, and a host of other economists produced a variety of models explaining the old stylized facts. But on the face of it, this would suggest that they cannot explain the markedly different new stylized facts. It would seem that a new set of theories is required.

This paper argues that only a slight (in the technical sense) modification of the old theories is required; but that while the modification may be technically small, this new theory has profound implications for how we view the economy, including for policy. Solow, and those working in the neoclassical tradition, assumed markets were competitive, and that output was produced with labor and capital, with a constant returns to scale production function. In that theory, rents played no role, because under those assumptions, there were no rents. We argue, however, that changes in rents, broadly defined - including land rents, exploitation rents, and rents on intellectual property - may be at the center of what has been happening; much of the increase in wealth is a result of the increase in (the capitalized value of) rents - and such increases do not increase, and may even decrease, economic output. Economic analysis should focus on how changes in technology (including innovations that may have enhanced the ability of those with market power to leverage that power), institutions, and policy may have increased these rents.

\section{Equilibrium theories}

This paper attempts to provide a set of coherent models that explain, or at least provide insights into, the new stylized facts. As in our earlier work, ${ }^{14}$ a key part of our analysis is the insistence that there be consistency between the 
micro-behavior of agents and the macro-behavior of the economy, and that crucial variables, like the rate of return on capital, be treated as endogenous.

The paper argues that we can best understand what has been happening as a shift from one equilibrium to another. Overall wealth inequality is related both to the transmission mechanisms for human and financial capital across generations and to life cycle savings. ${ }^{15}$ In the models explored here, there is an equilibrium distribution between inherited and life-cycle savings; but changes in key parameters can change that equilibrium.

The models presented here differ, however, from earlier work in the analysis of income and wealth distribution in four ways: (a) We explicitly consider models in which there is a second, non-produced, asset, land; (b) We develop models in which while many individuals' saving is primarily for life-cycle purposes, there are a group of "capitalists" who pass significant amounts of wealth across generations; (c) We consider the possibility that the economy might not be fully competitive, and that there could be changes in the degree of market power; and (d) Land can be used as collateral, and the value of land (or other fixed assets) may be affected by financial and monetary policies.

\section{The organization of the paper}

The paper is distributed in four parts. Part I provides an overview of the key anomalies presented by the new stylized facts, and explains how a focus on rents helps to resolve them. Part II re-examines the equilibrium wealth distribution within the context of a standard model without land. Part III takes up the observation of Part I that a large proportion of the increase in wealth is related to the increase in the price of real estate. It was understandable why land was ignored in earlier neoclassical models (including Solow's, and those, like my own, trying to explain inequality): in a modern economy, land is not a central input into production. But this is not quite true. About a quarter of GDP represents housing services, of which land rents represent a significant proportion. (See the discussion below.)

It was the omission of land that represents the most important lacuna in my 1969 theory of the equilibrium distribution of wealth and income, which this paper attempts to rectify. We develop several models explaining the determination of the price of land, demonstrating why much of the increase in wealth would go into the value of land. It has long been recognized that there is a close link between financialization and inequality (Galbraith, 2012). We provide a set of models detailing that relationship, describing how when some assets are collateralizable and others are not, a change in financial/monetary policy can affect the value of collateralizable wealth. We explain why the composition of wealth between capitalists and life cycle savers are different; and financial and monetary policies that differentially affect different assets can have accordingly a marked effect on wealth distribution. More generally, we argue that the way 
our credit system functions (or mal-functions) has played an important role both in the increase in the wealth-income ratio and in the increase in wealth inequality.

\section{Part I: Key Anomalies and Their Resolution}

The puzzles presented by the new stylized facts. As we noted in the introduction, economists had worked hard to explain the old stylized facts, and the theories they developed in response - and indeed theories developed over the past two hundred years - are challenged by the new stylized facts:

(i) The standard theories predict that the capital-labor ratio eventually is a constant. The new "theory" suggests that it is ever increasing (at a rate equal to $g-r$ ).

(ii) Standard growth theory begins with the observation that $r$, the rate of return on capital, is an endogenous variable. Among the most basic laws of economics is the law of diminishing returns. If capitalists continue to invest at a rate faster than the growth of the labor force, ${ }^{16}$ then the rate of return to capital should diminish. ${ }^{17}$

(iii) Standard theories suggest that if the capital-output ratio increases, it is because there has been an increase in the capital-labor ratio. ${ }^{18} \mathrm{An}$ increase in the capital-labor ratio should be associated not only with a decrease in the return to capital $r$ but as with an increase in wages; but as we have noted, wages have stagnated.

(iv) And while most (but not all) studies of the elasticity of substitution suggest that it is less than unity, capital deepening would imply an increasing share of labor - contrary to the new stylized facts. . $^{19,20}$

(v) It is hard to reconcile the increase in the wealth-income ratio with national income account data on savings. There is a large unexplained component, which we call the wealth (or wealth-income) residual.

It is thus hard to reconcile several of the new stylized facts with standard neoclassical theory, if we interpret wealth, $W$, in the usual way as capital, $K$. In the first two subsections, we elaborate on these puzzles, providing the resolution in section 2.3 .

\subsection{Key anomalies and their resolution}

1.2.1 The wealth-accumulation residual

Here, we focus on the last of the puzzles: how we can reconcile the magnitude of the increase in wealth (capital) with national accounting data on savings. 
Just as a matter of national accounting, if $s$ is the fraction of national income saved (net),

$$
\frac{d}{d t}(\log K)=\frac{s Y}{K}
$$

And

$$
\frac{d}{d t}\left(\log \left(\frac{K}{Y}\right)\right)=\frac{s Y}{K}-g
$$

Piketty and Zucman present data showing that the average net national savings rate of the US over the period $1970-2010$ is 5.2 percent, ${ }^{21}$ and that the average growth rate of the economy was 2.8 percent. The wealth-income ratio varied, beginning the period at just under 4 and ending at about 4.6. Thus, treating for the moment " $K$ " and " $W$ " as identical (2.2) would have predicted a decline in the wealth-income ratio, at an average annual rate of somewhat more than 1.5 percent, in contrast to the observed increase. If these numbers were accurate, the observed increase in wealth income ratios must come from somewhere else than the steady accumulation of capital goods. ${ }^{22}$

This can be thought of as the "wealth-accumulation residual" (analogous to the Solow residual - Solow had shown that capital accumulation could account for only a small fraction of the increase in productivity; the rest had to be explained somehow.) We will argue below that there is a simple explanation of the residual - the increase in the capitalized value of rents, including land rents.

We can reframe (2.2) to ask, what is the critical net savings rate such that there is an increase in the "real" capital-output ratio? Let $k$ be the effective capital-labor ratio, $g^{*}$ be the "natural" rate of growth of the economy, the sum of the rate of growth of population (work force) and the rate of labor augmenting technological progress, $\beta=W / Y$, and $\xi=K / W$, the ratio of the value of produced capital to wealth (which includes land); then

$$
\frac{d}{d t}\left(\log \left(\frac{K}{Y}\right)\right)=\frac{s Y}{K}-g^{*}=\frac{s}{\beta \xi}-g^{*}
$$

so that capital deepening (defined as an increase in the capital output ratio) occurs if and only if

$$
s>g^{*} \beta \xi
$$

If it were assumed that the US growth over the last forty years was close to its natural rate, 2.8 percent, $\beta=4$, and $\xi=1$ (land is an unimportant), then $s$ would have to be greater than 11.2 percent, more than twice the net savings 
rate for the US. More realistic, even if $\xi=.8, s$ would have to be greater than 8.9 percent. Given the US savings rate of 5.2 percent, only if $\xi<.46$ will there be capital deepening.

The US is an open economy, and there have been considerable capital inflows. These have varied considerably at a percentage of GDP. Assume capital inflows equal iY. Then

$$
\mathrm{d} \log (\mathrm{K} / \mathrm{Y}) / \mathrm{dt}=(\mathrm{s}+\mathrm{i}) \mathrm{Y} / \mathrm{K}-\mathrm{g}^{*}=(\mathrm{s}+\mathrm{i}) / \beta \xi-\mathrm{g}^{*}
$$

Thus, adding to the earlier parameters $(\beta=4 ; \xi=1 ; s=5.2$ percent) a reasonable value of $\mathrm{i} \approx 02, \mathrm{~d} \log (\mathrm{K} / \mathrm{Y}) / \mathrm{dt} \approx-1$ percent. Even taking account of capital inflows, the capital-output ratio falls at the rate of about 1 percent per year. ${ }^{23}$

Even if the savings rates were slightly higher, or the return to capital slightly higher, it is hard to generate plausible increases in the real capital stock that could account for the observed increases in the wealth-income ratios in recent decades. ${ }^{24}$

There is still a different way of looking at the puzzle of the increase in wealthoutput ratios. Over the past sixty years, a wide variety of models describing the growth of the economy have been formulated. In each, in the long run (steady state) there is a particular capital-output ratio. In each, changes in the underlying parameters (the rate of growth of the labor force, the rate of growth of labor-augmenting technological progress, and savings behavior) can explain a change in the long run capital-output ratio. The question is, have there been any changes in these parameters sufficient to explain/account for changes in the capital-output ratio and the factor distribution of income of the magnitude observed?

For instance, in the Solow growth model, the long-run capital-output ratio is given by $s / g^{*}$, where again $g^{*}$ is the long-run growth rate, equal to the rate of growth of labor supply plus labor- augmenting technological change, and $s$ is the savings rate. ${ }^{25} g^{\star}$ has varied, for instance increasing in the 1990 s and the first part of this century, while the savings rate (in the US) has decreased, which would suggest a decrease in the long-un capital-output ratio, not an increase let alone an increase of the magnitude asserted. ${ }^{26,27}$

\subsubsection{Can wages fall, the capital-output ratio increase,} and the return to capital not fall as $\mathrm{k}$ increases?

The previous section argued that in none of the standard models of economic growth can one plausibly obtain an increase in the equilibrium value of the capital-output ratio of the magnitude observed if we interpret wealth as capital. If one interprets " $W$ " as capital, then there has been not only an increase in the capital-output ratio, but also in the capital-labor ratio. Our ultimate objective is to understand the distribution of income, both among individuals and 
among factor shares. We now ask, can wages fall (as they have been) as $k$ (the capital-labor ratio) increases, within the standard neoclassical model.

Movements in average wages. Some have suggested that some forms of capital are like robots, and compete directly with workers, lowering their wages. But highly skilled workers still need to manage the robots, and even if the increased capital lowers the return to unskilled workers, it increases the return to the skilled workers. In Appendix A we show that under standard assumptions, an appropriately weighted average wage must increase.

Data for the United States, for instance, shows otherwise: a stagnating or declining average wage rate during the past four decades, during which the capitalmoutput ratio has increased - if we interpret "wealth" as capital. ${ }^{28}$

Movements in average productivity. Unfortunately, we typically cannot observe marginal productivities directly; but we do have data on average productivities, $\bar{P}=F(K) / L$. It should be obvious that (if nothing else changes) $\frac{d \bar{P}}{d K}=\frac{F_{K}}{L}>0$, i.e. average productivity should increase with capital deepening.

Direct data on average productivity is consistent with this hypothesis. Thus, if we are to believe in the competitive determination of wages, given the large disparity in the movement of, say, the average productivity of the bottom 99 percent and their average wage, then somehow a huge gap between movements in marginal and average productivities must have opened up - a gap that has yet to be explained. ${ }^{29}$

Technological change. There is a related hypothesis: that technological change has diminished the returns to unskilled labor. It is skill biased. ${ }^{30}$ While the timing of the changes in the share of labor and the decrease even in wages of relatively skilled labor in more recent years argues against skill biased technological change as the major or at least sole explanation of changes in distribution, ${ }^{31}$ here we focus on the analytics.

If there were a single type of labor, then labor-augmenting technological change increases the effective labor supply, and, everything else being the same, would reduce the effective capital-labor ratio, and hence the wage per effective labor unit. But each worker would represent a larger number of effective labor units, so whether the wage per worker increases or decreases would depend on the elasticity of substitution. ${ }^{32}$ Only if the elasticity of substitution is substantially below unity would wages fall. (As we noted earlier, interpretis substantially below unity would wa $K$ "implies an elasticity of substitution greater than unity, which would imply an increase in wages. Similar results hold in the longer run, when there is an adjustment in the capital stock..$^{33}$ )

Assume now there are two types of labor, skilled and unskilled, and technology is skilled biased, say increasing the productivity of the skilled workers, while leaving that of unskilled workers unchanged. Whatever the factor bias of technological change, it must move the factor price frontier outwards, 
which means that if the return to capital doesn't change, then the return to at least one of the two types of labor must increase. It is possible to show that if the return to capital remains unchanged, the average wage would have to increase ${ }^{34}$ Again, it is not easy to reconcile observed patterns of changes in factor prices with the theory. ${ }^{35}$

\subsubsection{The resolution of the seeming paradox: There is more}

\section{to wealth than capital}

The previous two sections argued that it is hard to reconcile the new stylized facts with virtually any form of the standard growth model under the assumption that the increase in wealth corresponds to an increase in productive capital. What then is going on?

The most plausible hypothesis is that wealth $(W)$ and capital $(K)$ are markedly different objects (as Piketty himself recognizes, but the full implications of which he does not take on board), and that wealth can be going up even as capital (as conventionally understood) is going down. If capital is not going up much (or even going down) in tandem with the increase in the effective labor supply, it would explain why the interest rate has not gone down. (As we note below, we need to go further to explain the failure of the average wage to rise.)

There are many forms of wealth that are not produced assets. Much of the increase in wealth in recent years is associated with an increase in the value of land. The increase in the value of land does not, however, mean that there is more land, and that therefore the productivity of labor should go up. And an increase in the value of land does not mean that the marginal productivity of capital should decrease. Once we sever the relationship between $K$ and $W$, all the paradoxes described in the previous section disappear.

Wealth as a measure of control over resources. The standard wealth income measure, constructed by adding up the money value of wealth and dividing it by the money value of income. Tracing how that ratio, and ownership of that wealth, evolves over time captures something that is important in our economy and how it is changing: control over resources. But changes in the wealth distribution, so measured, do not even necessarily reflect well the distribution of "wellbeing." For the bundles of goods bought by those at different income/wealth levels may differ - indeed, in some of the models below, the increase in wealth is closely linked to the increase in the price of a good which is consumed only by the rich, so that the increase in inequality in welibeing is markedly lower than the increase in money-wealth. ${ }^{36}$

But what is clear is that the measure of wealth so constructed is not a good measure of the relevant inputs into the production process - wealth could be going up, and yet any reasonable measure of inputs could be moving in the opposite direction. 
Index number problems and wealth as a measure of productive inputs. ${ }^{37}$ Not only are the concepts different, but there are difficult measurement problems involved in each. Both are aggregates, and an aggregate constructed for one purpose may not be appropriate for another. The "volume" of capital goods resulting from saving out of national income (letting consumption goods be the numeraire) will be affected by changes in the price of capital goods relative to consumption goods. And the effective increase in " $K$ " will also be affected by capital augmenting technological change. (Indeed, the two issues are closely related; because there are constant changes in the design of capital goods, one has to establish a "hedonic" index of equivalency.) If the only capital good were computers, the increase in the "volume" of $K$ from a given amount of savings would have increased enormously over time. In calculating aggregate " $K$," we have to add up capital of different types, whose relative prices and productivities are changing over time.

But even abstracting from these subtleties, and assuming that there were a single capital good, $K$, and a single fixed factor, land, $T$, we can easily see that movements in $\mathrm{K}$ do not adequately summarize what is happening to aggregate input (relative to labor). If land is a factor of production, ${ }^{38}$ then wages will be related to inputs of both $K$ and $T$. If $T$ is fixed, then the increase in $K$ has to be proportionally greater-possibly much greater - than the increase in labor supply to ensure that wages increase, to offset the failure of $T$ to rise.

In short, we need to add up $K$ and $T$ somehow to ascertain what is happening to the aggregate input, which we will refer to as $C$. How we add the two together matters a great deal. And what makes sense for one purpose or in the context of one model or an economy with one technology may not in another.

If $T$ and $K$ were additive in the production function i.e. $Y=F(K+T, L)$, then to assess what is happening to the aggregate input, which we call $C$, we simply add $K$ and $T$ up linearly. ${ }^{39}$ In the case of France, this aggregate " $C$ " has been going up more slowly than GDP, even though $K$ has been going up slightly faster than GDP (see Figure 1.1). ${ }^{40}$

On the other hand, we could have a production function of the form

$$
Y=F(C, L)
$$

where now

$$
C=K^{5} T^{1-\zeta}
$$

Then, since $T$ is fixed,

$$
\frac{d}{d t}(\log (C))=\zeta \frac{d}{d t}(\log (K))
$$


Other data problems. This section has explained why data on wealth do not reflect "capital." Several of the stylized facts involved inequality metrics. There are serious problems associated with measuring the factor distribution. Because our tax system taxes capital gains at a lower rate than ordinary wage income, there are incentives to try to recategorize labor income as capital income (for example, private equity and carried interest). Going the other way, large fractions of the income of banks is paid out in bonuses to their managers, and thus treated as wage income in the national accounts. Likewise for the managers in other corporations. But there is a fundamental difference between these payments and ordinary wages. To a large extent, the managers determine their own pay. Though often referred to as incentive pay, the link between pay and performance is weak, evidenced so clearly in the 2008 recession; ${ }^{41}$ the money can better be thought of as a return on the control rights of the firm. While such property rights normally are not sold or bought in open markets (though occasionally they are, often with much contestation), they are transferred from one group of managers to their successors, and in the process there can be a significant gift exchange (that is, a provision of even a more generous retirement benefit than was contracted for) in the expectation of a similar transfer upon their retirement. If we appropriately relabel such income as non-wage income, then the share of wages would have declined even more than shown by the standard data series. ${ }^{42,43}$

\subsubsection{Parsing out the wealth residual}

We argued in section 1.2.1 that it is hard to reconcile national savings data with the observed increase in wealth. There was what we referred to as the "wealth residual." There are, in fact, three reasons that W can increase without a concomitant increase in $K$, besides an increase in the value of land. There could be an increase in the value of other inelastically supplied factors. ${ }^{44}$ There can be an increase in the value of intellectual property. Or there can be an increase in what might be called "exploitation" rents. In the discussion below, we will use the term "market power" and "exploitation" interchangeably. The deviations from the competitive benchmark that we are interested in here take on many forms besides that classically associated with imperfect competition in product or labor markets. There can also be exploitation by corporate or other special interests of the public: indeed, it was in this context that the term rent-seeking first got coined.

Some of the increase in wealth, as we shall see, has as much to do with our accounting frameworks as with anything else. Some of these instances of an increase in measured wealth are actually associated with decreases in the effective productivity of the economy.

Changes in rents on land and other non-produced assets. In later sections of this paper we model the determination of land rents and the value of fixed 
assets. A decrease in the interest rate (normally associated with capital deepening) should lead to an increase in the value of such assets. As population increases, the scarcity value of particularly attractive sites (like land in the Riviera) becomes greater. Much of the value of land today is in urban areas; as the population in key urban centers increases, ${ }^{45}$ the value of land in these cities increases.

There is considerable evidence that recent decades have shown "a historically unprecedented boom in global house prices... Rising land prices explain about 80 percent of the global house price boom that has taken place since World War II." ${ }^{46}$ The increase in land prices thus accounts for much of the increase in wealth and wealth-income ratios.

There can be an increase in the value of any asset fixed in supply: The wealthy strive not just to own homes in the Riviera but also Renaissance paintings. Thus, the discussion of positional goods in Part IV of this paper applies to these other assets as well as to land. In a world with increasing population, and fixed supplies of depletable natural resources, the value of these resources too can be expected to increase. ${ }^{47}$

Changes in market power and exploitation. There is an increasing consensus that much of observed inequality - especially at the top - is associated with rent seeking, including the exercise of monopoly power. ${ }^{48}$ If monopoly power of firms increases, it will show up as an increase in the income of capital, and the present discounted value of that will show up as an increase in wealth (since claims on the rents associated with that market power can be bought and sold. $)^{49}$

The magnitude of the associated increases in the capital-wealth ratio from even a small increase in exploitation can be significant. A permanent increase in the share of capital by just 1 percent would, when capitalized at a real discount rate of 1.5 percent, imply an increase of the wealth-income ratio of .67; an increase of market exploitation leading to an increase in the share of capital by 5 percent would lead to an increase in the wealth-income ratio by more than $3 . .^{50}$

There is an extensive literature discussing why we might expect an increase in monopoly power in a modern economy, for example, as a result of network externalities (Katz and Shapiro, 1994) and the fixed costs associated with research (Dasgupta and Stiglitz, 1980). (Many of these arguments, however, are inconsistent with the assumption of a constant returns to scale production function.) So too, the transformation of the economy towards the service sectors may have increased the importance of local monopolies (see Greenwald and Kahn, 2009). Note that such increases in wealth are associated with a decrease in the economy's effective productivity, because they are associated with an increase in market distortions. Moreover, it is an implication of such exploitation that even though $\mathrm{W}$ is increasing, wages are decreasing. 
While increases in monopoly rents are the most obvious example of an increase in wealth not associated with an increase in the productive capacity of the economy, there are many other forms of exploitation which may have increased in recent decades; the capitalized value of any such change would show up as a change in wealth.

Elsewhere, we and others (Galbraith, 2012) have focused on the role of the financial sector in increasing inequality. The financial sector grew before the 2008 crisis from 2 percent to 8 percent of GDP. Profits grew to absorbing 40 percent of all corporate profits. There are reasons to believe that much of this might be associated with exploitation rents (including those associated with market manipulation, insider trading, predatory lending, ${ }^{51}$ and anticompetitive practices arising from their control of the payments mechanisms, giving rise as well to abusive practices in credit and debit cards, and so on) and capitalized in the value of wealth. Though there was some increase in the amount of wealth to be managed, the increase in the wealth-income ratio was not so substantial to account for the increase in the share of the financial sector; nor can that sector's remuneration be accounted for by the improvements in their management of the funds, and even less so, by any improvement in overall economic performance. ${ }^{52}$

If the financial sector improved its ability to exploit the poor through predatory and discriminatory lending practices and abusive credit card practices (and the resulting profits were not bid away because of imperfections of competition) then there would be an increase in standard metrics of wealth. ${ }^{53}$

Other forms of exploitation of consumers. The financial sector has perhaps deservedily earned a reputation for its ability to exploit $\ldots$ to take advantage of imperfections of information and limitations of individuals' ability to process information. But other sectors have also increased their capacity to create and exploit such imperfections. Behavioral economics has exposed a large number of "irrationalities" in individuals' behavior, instances for example in which individuals systematically overestimate some risk and underestimate others. Corporations have now begun systematically to exploit such irrationalities to increase their profits.

Successful corporate rent-seeking: transfers from the public sector to the private. There are more subtle forms of "exploitation." Government allows "too-big to-fail" banks. The value of those banks is higher than they otherwise would be, because of government risk-absorption. But the contingent liability of the government is not capitalized, and because this liability doesn't show up in the national balance sheet, it appears as if the wealth of the economy has increased. But with appropriate metrics (where the decreased wealth of wageearning citizens, as a result of the increase in the expected present discounted value of the higher taxes that they will have to pay to bail out the banks), just the opposite would have happened: we would have recognized that because of 
the distortions associated with too-big-to-fail banks, the productive capacity of the economy has been diminished; that the bail-outs are Pareto-inefficient, and that the wealth of the economy has been diminished. ${ }^{54}$

In each of these situations, a change in the flow of resources that accrues to "capital" gets capitalized in wealth, and the present discounted value of the decreased flow to the rest of the economy is not reflected in our wealth metrics. We don't, for instance, value the change in the stream of tax revenues to the government or the expenditures by the government or the reduced wages accruing to workers as a result of increased market exploitation.

Knowledge and information rents. Earlier, we explained how firms can generate rents by creating and exploiting information asymmetries. In a modern economy, there are many other ways by which knowledge and information differentials can give rise to rents. Insider trading and market manipulation (e.g. in the Libor and Foreign Exchange markets) are the most obvious examples. There are reasons to believe that much of the profits generated by high frequency trading is a sophisticated form of front-running, taking advantage of differential access to information (Stiglitz, 2014c). These information rents are often primarily distributive, increasing incomes of some individuals at the expense of others. In some cases, they even lead to Pareto inefficiency. ${ }^{55}$ When capitalized, however, they lead to an increase in wealth, even if net income is decreased.

Intellectual property. There is another, closely related and increasingly important category of assets, intellectual property. Here, there have been three factors contributing to the increased market value of intellectual property: there may be more knowledge; the value of any "piece" of knowledge increases as the size of the economy (other inputs) increase - knowledge and these other inputs are complementary; and more of knowledge has been privately appropriated, and hence shows up in wealth data. ${ }^{56}$ Knowledge that is freely available increases output, but doesn't show up in anybody's balance sheet and therefore would not normally be reflected in the national accounts as wealth. But changes in the intellectual property regime (what Boyle (2003) refers to as the enclosure of the knowledge commons) has resulted in an increase in the wealth of those who are given these property rights. ${ }^{57}$

Changes in discount rates and risk management. There is a further reason for an increase in the value of wealth without a concomitant increase in the physical productive capital stock: the rate of discount may fall - for example, because of a decrease in the interest rate - and this may induce large changes in the relative price of different goods (and in the price of capital goods relative to consumption). This was the essential issue in the Cambridge-Cambridge controversy some half a century ago, where it was observed that the value of capital and the choice of technique may be non-monotonic in the interest rate. ${ }^{58}$

In the private sector, the relevant discount rate is the after tax return, so that there are two offsetting effects on the value of wealth of an increase in 
the tax on capital. In the limiting case where before tax returns are unaffected, the value of an asset yielding a before-tax return of $\mathrm{R}$ every year would be unchanged i.e. $V=\frac{(1-t) R}{(1-t) r}=R / r$. The value of assets facing an average tax rate greater than that relevant for the discount rate will go down; and conversely if the average tax rate is smaller.

Changes in risk management and the ability to absorb risk can also have effects on the wealth-income ratio..$^{59}$ At the same mean and variance of the return to an asset, such changes lead to an increase in the certainty equivalent return, and therefore of the market value. If the improved risk management/ ability to absorb risk leads to a lower discount rate, the increase in market value can be even larger.

There can also be countervailing general equilibrium effects. Individuals may reallocate more of their wealth to assets with a higher risk and higher mean return, i.e. assets which (on average) have a lower capital-income ratio.

\section{Part II: Equilibrium Wealth Distributions in Neoclassical Models}

A key concern in the growing inequality in the United States and other advanced countries is the worry that we are giving rise to an inherited plutocracy. Piketty (2014) emphasized that if $s_{p}=1$ and the rate of interest were greater than the rate of growth, inherited wealth would increase faster than the growth in income. On the other hand, the fact that individuals are living longer and must save for their retirement means that life cycle savings is increasing, reflected in part in the huge increase in pension funds. ${ }^{60}$ In this section, we construct a simple model incorporating both inherited and life cycle savings.

We are able to obtain simple formulae describing the equilibrium share of wealth held by life cycle savers. Using these formulae, we can easily ascertain the effects of, say, tax policy or changes in the parameters of the economy. We show that an increase in the savings rate of workers (as a result, for instance of encouraging them to save more) has no effect on output per capita, but does increase the share of wealth of life cycle savers. Life cycle savings crowds out inherited savings. On the other hand, a tax on capital (even if it is paid disproportionately by the rich capitalists, with proceeds paid out to workers, and so is therefore viewed as progressive) will be so shifted that capitalists are unaffected and workers' income, including transfers, actually goes down, as does their share in national wealth. This bears out a general theme of this paper: tax policies have to be constructed to take into account general equilibrium incidence effects. 


\subsection{Savings models}

This section is divided into two parts. The first presents the basic model, while in the second, we assume all individuals have identical savings functions. The only difference is that when wealth is low enough, bequests drop to zero.

\subsubsection{Basic Model}

We assume two groups: There are workers who live two periods, and save for their retirement. ${ }^{61}$ Their savings is referred to as "life cycle savings." Then there are the capitalists, who save a fixed percentage of their income, $s_{p}{ }^{62}$ For simplicity, we use a discrete time model.

In this section, output is produced by means of a neoclassical constant returns to scale production function $\mathrm{Q}=\mathrm{F}(\mathrm{K}, \mathrm{L})$, where $\mathrm{K}$ is the capital stock and $\mathrm{L}$ the labor supply (there is full employment). $\mathrm{k}=\mathrm{K} / \mathrm{L}$ is the capital-labor ratio. $\mathrm{Q} / \mathrm{L}=\mathrm{F} / \mathrm{L}=\mathrm{f}(\mathrm{k})$ gives output per worker as a function of the capitallabor ratio. The return to capital is $\mathrm{f}^{\prime}$, and the wage rate is $\mathrm{f}-\mathrm{kf}^{\prime}$. We assume that the number of capitalists and workers increase at the same rate, $\mathrm{n}$ (assumed here to be exogenous.) (In this simple version, we ignore labor augmenting technological progress. It is straightforward to bring it into the analysis.)

The difference equations describing the evolution of the system are given by ${ }^{63}$

$$
(1+n) k_{t+1}^{c}=\left(1+s_{p} f^{\prime}\left(k_{t}\right)\right) k_{t}^{c}
$$

and

$$
k_{t+1}^{w}=(1+r) s\left(k_{t+1}\right) w\left(k_{t}\right) /(1+\mathrm{n})
$$

where $k^{w}$ and $k^{c}$ are workers' and capitalists' capital (per capita), respectively, where we have allowed the savings rate of workers to depend on the (rationally expected) interest rate, ${ }^{64}$ and where

$$
k_{t}=k_{t}^{w}+8 k_{t^{\prime}}^{c}
$$

where $B$ is the ratio of workers to capitalists. (By assumption capitalists supply no labor. Recall that $\mathrm{k}$, which enters the production function, is the ratio of the capital stock to workers, not the per capita capital stock.) $B$ is assumed to be fixed.

These equations fully describe the dynamics, given an initial value of workers' and capitalists' capital..$^{65}$ In the steady state, $k^{c *}=k_{t}^{c}=k_{t+1}^{c}$ and similarly for $\mathrm{k}^{\mathrm{w}}{ }_{\mathrm{t}}$. Hence, from (3.1)

$$
n=s_{p} f^{\prime}\left(k^{*}\right),
$$


where $k^{*}$ is the steady-state value of $k$ and $f^{\prime}\left(k^{*}\right)$ is the steady-state return on capital, equal to $r$. Note that $r$ here is the return over a generation, i.e. if a generation is 30 years, and the annual interest rate is 2 percent, $r \approx 1$. The steadystate level of capital (and the equilibrium interest rate) is determined simply by capitalists' saving propensity.

If workers save more, the economy does not become richer; income does not go up; wages do not increase. All that happens is that they increase their share of total capital.

The steady-state capital of workers (life cycle capital) given by (where we look at workers' wealth as of the beginning of their period of retirement, after earning interest, rather than at the end of their working life)

$$
k^{w^{*}}=\left(1+r^{*}\right) s\left(k^{*}\right) w\left(k^{\star}\right) / 1+\mathrm{n}
$$

Hence

$$
\frac{k^{w *}}{k^{*}}=\frac{s\left(k^{*}\right) w\left(k^{*}\right)}{(1+n) k^{*}}\left(1+r^{*}\right)
$$

Using (3.4) this can be rewritten

$$
\frac{k^{w *}}{k^{*}}=\frac{s\left(k^{*}\right) w\left(k^{*}\right)\left(1+\frac{n}{s_{p}}\right)}{(1+n) f^{\prime-1}\left(\frac{n}{s_{p}}\right)}=n \frac{s\left(k^{*}\right)\left(1+\frac{n}{s_{p}}\right)}{(1+n) s_{p}} \frac{1-S_{k}}{S_{k}}
$$

The ratio of wealth of life-cycle savers to that of capitalists (or to total wealth) depends on the relative savings rates, the relative shares (recall that $S_{k}$ is the share of capital), and the growth rate. A decrease in the growth rate would (if the elasticity of substitution is less than one and if the savings rate did not change) lead to an increase in the capital-labor ratio and a decrease in the share of capital. There is a critical value of the elasticity of substitution, such that below that threshold, a decrease in the growth rate leads to an increased share of life-cycle savings, and above that threshold, it leads to a decreased share. (The rate of return to capital does not enter into this formula, because it is an endogenous variable. But this analysis has ignored the effects on workers' savings rate: A decrease in the growth rate leads to a lower interest rate, and this can lead to either a higher or lower value of $s$ depending on the sign of $\left.s^{\prime}.\right)^{66}$

If the savings rate of workers increases, for instance because of increased expected retirement longevity, ${ }^{67}$ workers' wealth increases proportionately, while aggregate wealth remains unchanged. By the same token, in this model, if the 
generosity of social security increases, so the savings rate of workers decreases, workers' wealth (excluding their claims on social security) decreases proportionately, while aggregate wealth remains unchanged (in a pay-as-you-go system).

There is an important qualification to this analysis: workers' savings has to be low enough so that, on their own, they do not drive the rate of return below $\mathrm{n} / \mathrm{s}_{\mathrm{p}}$. For if they do, then the life cycle savers eventually drive out the capitalists. ${ }^{68}$ It would appear that this condition is normally satisfied.

Market distortions The analysis so far has assumed that workers are able to get the same return on their investments as capitalists. We then obtain

$$
\frac{k^{\wedge w *}}{k^{\wedge *}}=n \frac{s^{*}\left(1+\left(\frac{n}{S_{p}}\right) \zeta\left(1-\tau^{\mathrm{cw}}\right) /\left(1-\tau^{c c}\right)\right)}{S_{p}(1+n)} \frac{1-S_{k}}{S_{k}}
$$

where $r^{w}$, the return workers receive on their investments, is $\varsigma$ times that of capitalists, and $\tau^{\mathrm{cw}}$ is the effective tax rate on the return to capital for life cycle savings, $\tau^{\text {cc }}$ that on the return to capital for capitalists. Thus $\frac{k^{\wedge w *}}{k^{\wedge *}}$ will be lower than suggested by the basic model if (a) a distorted financial market delivers to life cycle savers lower returns than those received by capitalists; and (b) regressive taxation leads to life cycle savers facing higher tax rates (than those confronting capitalists). An example of the former that has recently been exposed is how conflicts of interest among those managing large fractions of IRA accounts lead to substantially lower returns on those accounts. Part II provided several other reasons for why life cycle savers might receive lower returns on their investments than do capitalists. The share of life cycle savings will be further lowered if, as we suggested in section 2 , because of monopolies and other distortions the share of capital is larger than it would have been in a competitive equilibrium.

\subsubsection{The effect of taxation}

If we impose a tax on capital at the rate $\tau^{c}$, we obtain instead of $(3.4)$

$$
n=\left(1-\tau^{c}\right) s_{p} f^{\prime}\left(k^{*}\right)
$$

implying that the after-tax return to capital is not affected by the tax (just as was the case in the Kaldor model). There is, in effect, full "shifting." As the tax rate increases, the equilibrium capital stock diminishes. ${ }^{69}$

Capital taxation with proceeds distributed to workers. To ascertain the effect on the relative importance of lifecycle savings, we have to specify what happens 
to the tax revenue. Assume it is redistributed to workers. Then the transfer T (per capita) is given by

$$
\mathrm{T}=\tau^{\tau} r\left(k^{*}\right) k^{*}
$$

Noting that in our simplified model, the saving rate depends only on the after tax rate of return, and from (3.4a) that is unchanged, and letting $\mathrm{s}^{*}$ denoted that value of $s,(3.6)$ can be rewritten as

$$
\frac{k^{w *}}{k^{*}}=\frac{\left(1+\frac{n}{s_{p}}\right) s^{*}\left(w\left(k^{*}\right)+\right)}{(1+n) k^{*}}
$$

Then, to ascertain the effect of an increase in the tax rate on the share of inherited wealth, we simply have to ascertain the sign of

$$
\frac{d\left(\frac{s^{*}\left(w\left(k^{*}\right)+\mathrm{T}\right)}{k^{*}}\right)}{d \tau^{c}} .
$$

Normally, an increase in the tax rate lowers the wage, but at least for low $\tau^{c}$ increases the transfer.

Workers' lifetime income $Y^{W}=w\left(k^{*}\right)+T$, so that ${ }^{70}$

$$
\frac{d Y^{W}}{d \tau^{c}}=\left(-k^{*} f^{\prime \prime}\left(k^{*}\right)+\tau^{c}\left(k^{*} f^{\prime \prime}\left(k^{*}\right)+f^{\prime}\left(k^{*}\right)\right)\right) \frac{d k^{*}}{d \tau^{c}}+r\left(k^{*}\right) k^{*}
$$

Where

$$
\frac{d k^{*}}{d \tau^{c}}=\frac{f^{\prime}\left(k^{*}\right)}{\left(1-\tau^{c}\right) f^{\prime \prime}\left(k^{*}\right)}
$$

The sign of (3.11) is thus that of $\frac{\tau^{c}\left(f^{\prime}\left(k^{*}\right)\right)^{2}}{\left(1-\tau^{c}\right) f^{\prime \prime}\left(k^{*}\right)}<0$ for $0<\tau^{c}<1$. $\left(\frac{d Y^{W}}{d \tau^{c}}=0\right.$ at $r^{c}=0$.)

Hence, the loss in wages is always greater than the benefit from the transfer.

It follows that an increase in the interest income tax always increases the relative importance of inherited wealth..$^{71}$

The tax also has an adverse effect on the distribution of consumption (wellbeing). Since the after-tax interest rate facing capitalists is the same, their flow of consumption (in steady state) is unaffected. Workers' lifetime utility is a function of their income, $Y^{W}$, and the interest they receive on their savings (after tax). We have already shown the derivative of $Y^{W}$ with respect to $\tau^{c}$ is negative (except at $\tau^{c}=0$, where it is zero). But because the after-tax return the 
worker receives from his investment is unaffected, workers are unambiguously worse off.

Thus, in the case that would seem to be the most favorable to workers - where all the proceeds are redistributed to them - their income is reduced, their welfare is reduced, and inequality is increased.

Inheritance tax with proceeds distributed to workers. With an inheritance tax, there is still tax shifting: wages fall and the before-tax return on capital for capitalists increases. Appendix $\mathrm{C}$ shows that the relative share of life cycle savings may increase, so long as the elasticity of substitution is not too small, and that there is an optimal tax rate, maximizing workers' wellbeing.

Public investment. So far, the results of this section on the ability of the government to improve the wealth distribution through capital taxation are somewhat disheartening. If, instead, government invests the tax proceeds as well as the proceeds it gets from its investments, then an increasing fraction of the capital stock will be owned by the government. The government investment drives down the return to capital, so that the wealth of the capitalists can't keep up with the increase in population. Their wealth diminishes (per capita), and we get a new equilibrium which is similar to the original equilibrium except that now the government owns all the capital and, in effect, its saving rate is unity. Then wages are higher, and workers are unambiguously better off. Note that this would be true even if the government were slightly less efficient than the private sector. ${ }^{72}$

If we expand the model to a three-factor production function, $Y=F\left(K_{p}, K_{g z} L\right)$, with private and public capital goods, and (some of) the proceeds from the tax are invested into the public capital good, then it is easy to show that there can be a new equilibrium in which a (somewhat poorer) capitalist class survives but the tax may still have a positive effect on workers: In a three-factor production function, $K_{p}$ and $L$ can be substitutes, and $K_{g}$ and $L$ can be complements, so that on both accounts, wages are increased as a result of the tax; but the increase in $K_{g}$ is consistent with the after tax return to capital returning to its previous level..$^{73}$

Progressive capital taxation ${ }^{74}$ A progressive capital income tax can affect the degree of inequality among the rich. ${ }^{75}$ The argument for a progressive capital tax is strengthened if we look more carefully at the nature of the measured returns to capital. In economists' simplest models, all capital receives the same returns. If returns are stochastic, then it is simply luck that determines who gets high returns. If that were all that there were to the matter, a progressive tax on the rate of return to capital in excess of the average return (with offsets for returns below that level) would be welfare increasing, if capitalists were risk averse. If savings were elastic in the certainty equivalent return, then savings would increase, and workers would be better off.

There may, however, be other possible explanations for above average returns. The returns could represent greater skill at investing, in which the returns 
ought to be viewed as a return to labor, not as a return to capital. ${ }^{76}$ The returns could represent a return to risk taking. If capital markets are imperfect (so risk is not fully diversified) and individuals are risk averse, riskier investments will yield higher returns than safe. A proportional capital tax on excess returns (over the safe rate of interest) would, under these circumstances, increase risk taking, and thereby average incomes. Finally, the returns could in part be a return to exploitation. To the extent that that is the case, ${ }^{77}$ then a progressive tax would discourage such rent seeking behavior, increase economic efficiency, improve the wellbeing of those who are being exploited, and reduce overall inequality.

\subsubsection{Toward a more general model}

The previous subsection assumed that society is composed of two groups of individuals - workers who engage in life cycle savings, and capitalists who pass on wealth from one generation to the other. In fact, however, all individuals could have the same savings function; it is simply past circumstances that determine the observed savings rate. Assume, for instance, that providing bequests is a "luxury," and that when individuals' wealth exceeds a certain level, they begin to act like capitalists, passing on money to their heirs.

We assume gross savings of any individual are a function of his end of period wealth, which is just his wage and the return on the capital from the previous period: $s\left(W_{t}\right) W_{t}$, where

$$
W_{t}=w_{t}+\left(1+r_{t}\right) k_{t}
$$

But assume $s\left(W_{t}\right)$ is S-shaped, the extreme version of which would be $s=s_{0}$ for $W \leq W^{*}$ and $s=s_{1} \gg s_{0}$ for $W>W^{\star} .^{78}$ Then there exists a two-class equilibrium. To see the nature of the equilibrium, assume a fixed fraction of the population $\vartheta$ are in the upper income group. Then

$$
\begin{gathered}
s_{i}(w(k))+\left(1+r(k) k_{i}\right)=(1+n)\left(k_{i}\right) i=0,1 \\
k=\vartheta k_{1}+(1-\vartheta) k_{0}
\end{gathered}
$$

For each value of $\vartheta$, there is a different equilibrium, that is, $k_{i}=k_{i}(\vartheta)$.

Special cases of this model yield the standard Solow and Kaldor/Pasinetti/life cycle model. If $\vartheta=0$, we obtain the discrete variant of the Solow model. On the other hand, if $s_{0} \approx 0,(3.14)$ can be approximated by

$$
s_{1}\left(1+r(k)+\frac{\vartheta}{k} w(k)\right)=1+n
$$

Here, it is not that the workers have a different savings function from that of the capitalists; it is only that their income is low so they save little. Most 
importantly, we have endogenously derived a two-class model out of a S-shaped savings function.

In this model $\vartheta$ is determined just by history. For each, there is a steady state $\left(\mathrm{k}_{1}, \mathrm{k}_{2}\right)$. Individuals never leave the "class" into which they are born. But it is easy to construct a stochastic model in which some in the upper class have bad luck and move down, and some in the lower have good luck and move up. $\vartheta$ is then solved for endogenously, related to the transition probabilities (see Stiglitz, 2015b). Changes in policy, behavior and technology (the savings functions, the stochastic processes) can move the economy from one in which most individuals are in the "upper group" (the middle class society of the past) to one in which most are in the lower group (the "99 percent/1 percent society of the present.) Financial sector "innovations" that encouraged those at lower wealth not to save and regressive capital taxation might, for instance, accomplish this.

\section{Part III: Land Rents}

In section I of this paper, we noted that standard neoclassical models focusing on capital and labor in competitive markets could not explain the increase in the wealth-output ratio observed in the US and many other advanced countries and other stylized facts of modern economies. ${ }^{79}$ Central to our resolution of these puzzles, we suggested, was the understanding that wealth and capital were different concepts. The most important source of the disparity between the growth of wealth and the growth of productive capital is the growth of the value of land - not associated with any increase in the amount of land and therefore of the productivity of the economy. ${ }^{80}$

In this part, we present a series of models that might account for much of the increase in the value of wealth taking the form of an increase in the price of land. These models not only help us understand the increase in the wealthincome ratio, but also the increase in wealth inequality. This part is divided into five sections. In section 1.4, we extend the life cycle/inheritance model of section 1.3 to land. Section 1.5 presents the simplest model with land rents, showing that even in this very simple model, the increase in wealth may be markedly greater than the increase in capital. Section 5 examines land as a positional good, deriving a similar result that increases in wealth are greater than increases in capital. Section 1.6 investigates the dynamics of land prices, showing that in a natural formulation, bubbles can easily arise, and along such "bubble paths," wealth may increase, even though capital (per capita) is decreasing. In effect, wealth accumulation in the form of land may crowd out real capital accumulation. ${ }^{81}$ The final section explores how financial and monetary policies can give rise to an increase in land prices and thus "wealth," but such increases in wealth may have little to do with what is happening to 
the real wealth of the economy - which in this simple model is reflected in the value of the capital stock (per capita.)

There is one further (important) explanation of an increase in land values: the increase in urbanization leads to an increase in urban land values, the value of being in proximity to urban centers..$^{82}$

\subsection{Land in a life cycle model}

In section 1.3, we formulated a life cycle model, and used it to explain the division of wealth between capitalists and workers (life time savers). It is easy to incorporate land into this framework. Now, however, because land is a store of value that is alternative to capital, there is an important question: could savings that otherwise be used for capital accumulation be deflected into land, thereby harming workers?

\subsubsection{Pure life cycle model}

We begin our analysis with the case where there are only life cycle savers, but there is a fixed asset, which we will call land.

It is useful to rewrite (3.2) to focus on "savings in capital":

$$
s(w(k), r(k)) w(k)-\frac{f_{T^{\wedge}}}{f_{k}}=k .
$$

Any value of $k$ solving (4.1a) is a steady-state equilibrium.

There can be multiple equilibria, as illustrated in Figure 1.2. As $k$ increases, wages increase. The slope of the LHS can be greater or less than unity, and can vary with $k$, so that the LHS can cross the 45 degree line more than once. There is a natural sense in which stability requires that the savings curve cut the 45 degree locus from above, i.e. the increase in savings into capital from an increase in the capital stock is less than the increase in the capital stock itself.

Looking across (steady-state) equilibria, it is clear that, letting $W$ denote wealth per capita.

$$
\frac{d W}{d k}=\frac{d}{d k}\left(k+\frac{f_{T^{\wedge}}}{f_{k}}\right)=1+f_{T^{\wedge} k} / f_{k}-f_{r^{\wedge}} f_{k k} / f_{k}^{2}
$$

If

$$
f_{T^{\wedge} k} / f_{k}-f_{T^{\wedge}} f_{k k} / f_{k}^{2}>0,
$$

then $W$ increases more than $k$. That will always be the case if $T^{\wedge}$ and $k$ are complements. 


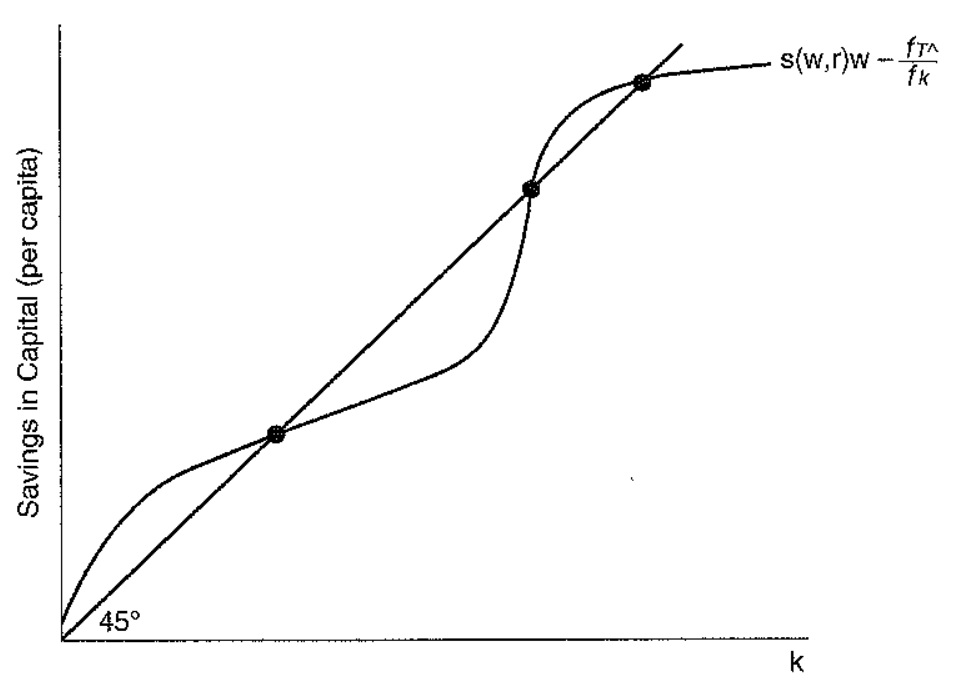

Figure 1.2 Multiple equilibria in pure life cycle mode

By the same token, we can ask what happens if there is an upward shift in the savings function, i.e. the savings function is given by $\gamma s(w(k), r(k))$. Then

$$
\frac{d k}{d \gamma}=\frac{s w}{\left(1+f_{T^{\wedge} k} / f_{k}-f_{T^{n}} f_{k k} / f_{k}^{2}\right)(1+n)-\gamma S w^{\prime}-\gamma w \frac{d s}{d k}}
$$

while, from (4.2),

$$
\frac{d W}{d \gamma}=\frac{d W}{d k} \frac{d k}{d \gamma}=\left(1+f_{T^{k} k} / f_{k}-f_{T^{\prime}} f_{k k} / f_{k}^{2}\right) \frac{d k}{d y} .
$$

Again, we get the result that $W$ can increase more than $k$. Some of the increased savings goes into an increased value of land, reducing the benefits that otherwise would have accrued to a higher savings rate.

Taxing capital. A tax on the return to wealth (both land and capital) will shift the function $s w-f_{T} / f_{k}$ up or down depending on whether $s$ is decreasing or increasing in $\mathbf{r}$ (increasing or decreasing in $\mathrm{k}$ ), which implies that in a stable equilibrium, it will lead to an increased or decreased value of $k$ depending on whether $s^{\prime}$ is greater or less than zero. The change in wealth will typically be larger than the change in $k$ (so long as inequality (4.3) is satisfied). But while in a two-factor production function, a decrease in $k$ necessarily leads to a lower wage, now it may not. Capital and labor may be substitutes rather than complements. (Robots may be a substitute for unskilled labor.) 
Taxing land. It is easy to see that in this model, a tax on the value of land the proceeds of which are distributed to workers results in an increase in investment and a reduction in the return to capital (in a stable equilibrium). ${ }^{83}$ If $\mathrm{F}_{\mathrm{KL}}>0$ (labor and capital are complements) wages will rise. A fortiori, if the revenues are fully invested, wages go up even more.

\subsubsection{A two-class model}

In this section, we return to our two-class model of section 1.3, but introduce land. For simplicity, we focus only on the steady state. ${ }^{84}$ But this poses a problem in the absence of land-augmenting technological change and population growth: if the equilibrium interest rate would go to zero (as it would if $n$ were equal to zero), the value of land would go to infinity. There are at least two ways out of this puzzle: (a) assume land does not yield any return or (b) assume land augmenting technological progress at the rate $\mathrm{n}$. Here, we take the latter tack, and express all units in per capita terms (per unit of effective land).

The variables of interest can all be expressed as functions of $k$. The returns to land must equal the returns to holding capital. In steady state, the price of a unit of effective land, denoted by $q$, will be constant. Letting $f_{T^{\wedge}}$ denote the marginal return of a unit of effective land, which in steady state is constant, $q=\frac{f_{T^{\wedge}}}{f_{k}}$, in the obvious notation, where wages and returns to capital are functions of the capital stock per capita. Savings are put either into capital goods or into land holdings.

Instead of (3.1) the capitalists' wealth accumulation equation is described by

$$
k_{t+1}^{c}+q_{t+1} T_{t+1}^{c}=W_{t+1}^{c}=\frac{k_{t}^{c}+q_{t} T_{t}^{c}+s_{p} f_{k}\left(k_{t}\right)\left(k_{t}^{c}+q_{t} T_{t}^{c}\right)}{1+n}=\frac{\left(1+s_{p} f_{k}\left(k_{t}\right)\right) W_{t}^{c}}{1+n}
$$

where $T_{t}^{c}$ is the effective landholdings of the capitalists at time $t$ (here, per capita) and $\mathrm{q}$ is the price of an effective unit of land. In steady state, the return to capital and the return to land (the return to each of the assets) is the same. The rate of interest must be equal to the rate of growth divided by the savings propensity of capitalists, as before, and that implies a particular value of $k=k^{*}$. We similarly rewrite (3.2) as (continuing with the obvious notation)

$$
W_{(t+1)}^{w}=s\left(k_{(t+1)}\right) w_{t}^{w} / 1+n .
$$

Hence, the steady-state equation for life cycle wealth relative to total wealth is now just

$$
\frac{W^{w *}}{W^{*}}=\frac{s\left(k^{*}\right) w\left(k^{*}\right)}{(1+n) W^{*}}=\frac{s\left(k^{*}\right) w\left(k^{*}\right)}{k^{*}(1+n) W^{*}} k^{*}=n \frac{s\left(k^{*}\right)}{(1+n) s_{p}} \frac{1-S_{k}}{S_{k}(1+x)} .
$$


where $x \equiv$ the ratio of the value of land to capital. In this case, $q^{*}=\frac{f_{T^{\wedge}}}{f_{k}-n}$.

Changes in worker savings have no effect on wealth; an increase in capitalists' savings rate leads to an increase in $k$, with an effect on wealth that is normally greater than the increase in $\mathrm{k}$ because of the increased value of land, as in the earlier model.

We can easily study the effect of various forms of taxation on the distribution of income and wealth (between capitalists and life-cycle savers); these effects are markedly different than in the pure life cycle model of the previous subsection because of tax shifting. Land taxation has no effect on $k^{*}$, hence no effect on wages; it leads to a diminution of the value of wealth. If the proceeds of the tax are distributed to workers, life cycle wealth is increased, and therefore on both accounts, wealth inequality is reduced. (Similar results hold for land capital gains taxes.) Inheritance taxation, as in section 3 , leads to an increase in the before tax return on capital, lowering $\mathrm{k}$. If capital and labor are substitutes, then capital and land have to be complements, and the tax on inherited capital unambiguously reduces wealth inequality. Wages go up and the return to land goes down, so the share of wealth held in life cycle savings unambiguously goes up. But if capital and labor are complements, the opposite may happen. ${ }^{85}$

\subsection{A simple model with land rents}

To see more clearly the relationship between wealth and capital, we can formulate an even simpler model than the life cycle model of the previous section. Assume the rents associated with land are fixed and last in perpetuity, while the production of industrial goods requires no land. Then a slight decrease in the (long-term real) interest rate can lead to a large increase in the value of land ${ }^{86}$ Thus, national output is given by

$$
Q=F(K, L)+R
$$

where $\mathrm{Q}$ is total output, $K$ is productive capital and $L$ is labor, for the moment assumed fixed, $\mathrm{F}$ is constant returns to scale, and $\mathrm{R}$ is the fixed return to land. Then the value of wealth, $W$, is given by ${ }^{87}$

$$
W=K+\frac{R}{r}=K+R / F_{K}
$$

where $r$ is the rate of interest (return on capital, equal to $F_{R}$ ) so that

$$
\frac{d W}{d K}=1-\frac{R F_{K K}}{F_{K}^{2}}>1
$$


If $F$ is, for instance, a unitary elasticity of substitution production function, with coefficient on capital of $\alpha$, then

$$
\frac{d W}{d K}=1+\frac{R}{Q-R} \frac{1-a}{a}
$$

If, for instance, $R / Q=.3$ and $\alpha=.2$, then $d W / d K \approx 1+1.7=2.7$ the increase in wealth is more than twice the increase in the productive capital.

The effect of taxation. If the return to land is taxed, then $W$ and $K$ are more closely aligned. If the returns to land are fully taxed (as they would be with the Henry George tax), $W$ and $K$ would be fully aligned. This follows directly from rewriting (5.2) as

$$
W=K+\frac{\left(1-\tau^{L}\right) R}{r}=K+\left(1-\tau^{L}\right) R / F_{K},
$$

where $\tau^{L}$ is the tax rate on the returns to land.

\subsection{Positional goods}

Similarly, if land serves as a positional good, there can be an increase in the value of land, without any increase in the productive potential of the economy. Rich individuals compete for houses in the Riviera. As the rich get richer, they compete more vigorously for this real estate, and the price of this fixed asset increases, without any increase in "real" output.

Assume there are some assets in fixed supply (positional goods) that do not affect production of conventional goods. Assume all the wealth of the economy is held by the rich (an assumption which does not depart too far from reality) and that the demand by rich for these goods is given by $M(W, p)$ with the equilibrium given by

$$
M(W, p)=p T
$$

where $p$ is price of land, $T$, which is fixed supply, and $W=K+p T$. For simplicity, where $p$ is price of land, $T$, which is be solved for $p$ as a function of $W$, and $K$ can then be solved for

$$
K=W-p(W)
$$

Then

$$
\frac{d K}{d W}=1-p^{\prime}=1-\frac{M_{w}}{1-M_{p}}<1
$$


If the wealth elasticity of the demand for positional goods is large enough and the price elasticity is small enough, then an increase in $W$ may even be associated with a decrease in $K$.

The effect of land taxation. As in the previous section, land taxation (and in more dynamic models, the taxation of capital gains on land) can help align $K$ and $W$. The demand for positional goods depends not just (or even so much) on the price as on the "user cost" or opportunity cost: $\mathrm{M}(\mathrm{W}, \mathrm{p}, \mathrm{u})$. The opportunity cost is $r$, the return on capital. If there is a land tax, the cost of owning the positional good becomes $r+\tau^{\underline{x}} p$. (In more general dynamic models, where the value of land is increasing, the user cost is $u=r+p\left[\tau^{L}-\left(1-\tau^{c g}\right) \frac{d \log p}{d t}\right.$, where $\tau^{c g}$ is the tax rate on capital gains.) Instead of (6.1) we have (6.1') $\mathbf{M}\left(\mathrm{W}, \mathrm{p}, r+p\left[\tau^{L}-\left(1-\tau^{c g}\right) \frac{d \log p}{d t}\right]\right)=\mathrm{p}$ which for fixed expectations about capital gains and zero capital gains tax rates can be solved for $\mathrm{p}$ as a function of $\mathrm{K}, \mathrm{W}$, and $\tau^{L}$ We can then rewrite (6.2) as

$$
K=W-P\left(W, K, \tau^{L}\right)
$$

At any given $K$, the higher $\tau^{L}$, the lower wealth: the tax reduces the gap between wealth and capital. ${ }^{88}$

Inequality in wellbeing. While in this and other models in this section, the increase in wealth may be largely (or entirely) due to an increase in land values, one might ask: does this lead to real inequality. After all, the rich consume the positional goods. The increase in land values affects them, and them only. Workers are only affected to the extent that the increase in land values crowds out capital accumulation, so $K$ decreases (or does not increase as much as it otherwise would.)

While this conclusion is true in the simplified model we have constructed here, it is natural that there be a spill over to workers (and in practice, such spillovers typically occur.) Assume, for instance, landlords/capitalists rent out some of their land to workers, at a rental price of $p F_{K}$. Then, policies and behavior which lead to an increase in $p F_{K}$ disadvantage workers.

Still, the observation that the increase in land prices (or of other positional goods) disproportionately affects the wealthy has several important implications. First, it reminds that in making comparisons across different income groups, we have to take into account the different market baskets of goods that they consume. The increase in the relative prices of positional goods means that there may not have been as large an increase in inequality as would appear to be the case. ${ }^{89}$

Secondly, it helps explain differences in savings behavior both over time and across income levels. To achieve "success" as demonstrated by acquiring expensive positional goods may require more savings (more wealth) today than 
when the price of such goods were lower. It may be that there is a difference between savings out of capital gains, especially those arising from the increase in the value of real estate, and other returns to capital, precisely because of the consequences of those price changes for acquiring the goods in the future that the rich seek to purchase.

Thirdly, by the same token, patterns of inheritances and life-time giving across generations too may be endogenous, affected in particular by such changes. If increases in real estate prices make it difficult for even reasonably successful workers to purchase a home that they and their parents believe is appropriate to their station in life, wealthy parents will provide larger intra vivo transfers. Note that, in some sense, the direction of causality has changed: greater wealth and wealth inequality arising from an increase in real estate prices has led to greater inheritances and intra vivo transfers across generations among the top..$^{90}$

Foreign ownership. The demand by foreigners for positional goods may lead to an increase in the wealth of the citizens of a country as well as to an increase in wealth inequality. Assume, as above, rentiers own all the positional goods (land in the Riviera). A sudden and unanticipated increase in the desire for these pieces of land by foreigners increases their value, and the wealth of those who happened to own this land; and if those within the country are the wealthy, it will contribute to the increase in inequality within the country. (This seems to have been a factor increasing inequality within several countries.)

\subsection{Bubbles: the dynamic instability of the market economy}

Bubbles are a pervasive and recurrent aspect of market economies. While the recession may have represented a "correction," the economy may not have fully corrected the price of real estate. ${ }^{91}$

Hahn and Shell-Stiglitz ${ }^{92}$ showed the dynamic instability of the economy with heterogeneous capital goods in the absence of a full set of futures markets extending infinitely far into the future (or without perfect foresight extending infinitely far into the future). The steady state was a saddle point.

The same result also holds for a model with capital and land (with two state variables, $K$, the stock of capital, and $p$, the price of land). We extend the production function in the straightforward way so that $Y=F(K, L, T)$, where, as before, $T$ is the supply of land and $L$ is the supply of labor, and $F$ is constant returns to scale..$^{93}$

There is a delicate problem: without growth of the labor force, the equilibrium interest rate will be zero in the long run in the Kaldor model. ${ }^{94}$ But at a zero interest rate, if there are positive returns to land, the value of land becomes infinite - in effect, the model breaks down. Assuming labor growth (or labor augmenting technological progress) poses its own problems: the landlabor ratio goes to zero, and under normal assumptions about the production 
function, the return to land itself would go off to infinity. This problem can in turn be "solved" by assuming just the right amount of land-augmenting technological progress. At first blush, this seems unpersuasive: why should nature produce land-augmenting technological progress in just the right amount to sustain a steady state. But upon reflection, it may not be so coincidental, once we introduce a theory of endogenous factor bias. We know that the bias is determined by relative shares, and if the elasticity of substitution is less than one, as land becomes more scarce, there are greater incentives for landaugmenting technological progress. ${ }^{95}$

We investigate two alternative approaches. The first entails assuming a conventional production function (without land), but the existence of land as a store of value. The second assumes a fixed rate of land augmenting technological change, equal to $n$.

\subsubsection{Non-productive land ${ }^{96}$}

The key equilibrium condition is that the return to holding land and capital must be the same, i.e. since land is non-productive, its entire return is its capital gain, $\frac{d}{d t}(\log p)$, and the equilibrium condition is

$$
\frac{d}{d t}(\log p)=\left(F_{K}-\mu\right)
$$

where $\mu$ is the depreciation rate and $F_{K}$ is the gross return to capital.

The short-run dynamics are described by (7.1) and

$$
\frac{d K}{d t}+T \frac{d p}{d t}=s\left(F_{K} K-\mu K+T \frac{d p}{d t}\right)
$$

where we have assumed that only capitalists save and they save a fixed fraction, s, of "full net income" including capital gains (Shell, Sidrauski, and Stiglitz, 1969). ${ }^{97}$ The RHS of (7.2) is net savings (as seen by the individual, not according to the national income accounts). This goes into an increase in the value of land ("land savings") or capital accumulation.

Substituting (7.1) into (7.2), we obtain (again using the normalization that $T=1)$ :

$$
\frac{d K}{d t}=s\left(F_{K} K-\mu K\right)-(1-s) \frac{d p}{d t}=(s K-(1-s) p)\left(F_{K}-\mu\right)
$$

(7.3) and (7.1) provide a pair of differential equations fully describing the dynamics of the economy. 


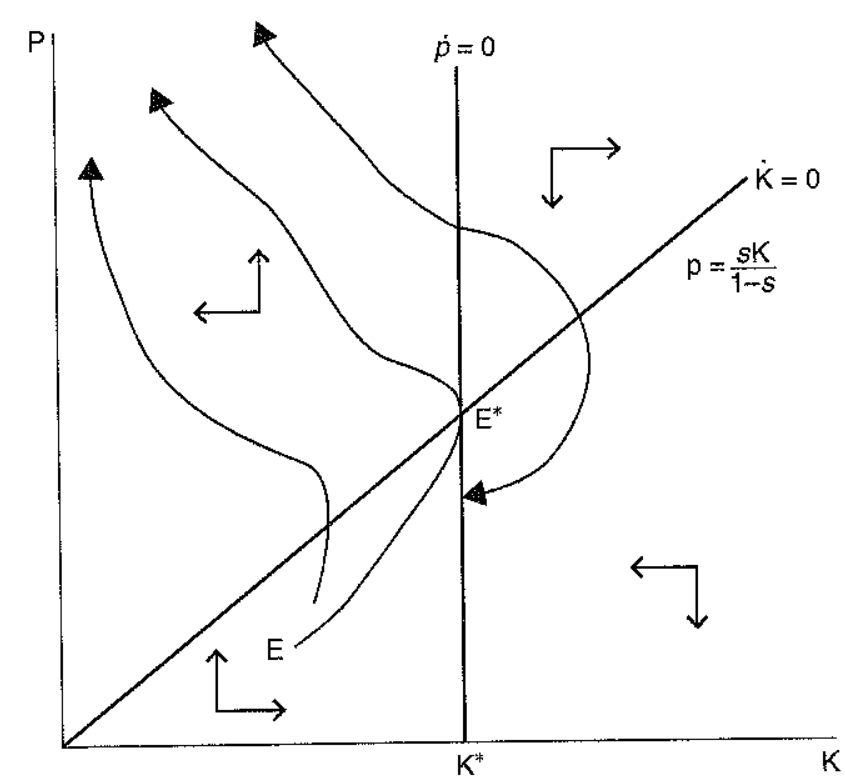

Figure 1.3 Steady states and dynamics with non-productive land: linear savings

Figure 1.3 shows the steady states, given by the solution to the loci

$$
F_{K}=\mu
$$

And

$$
p=s K /(1-s)
$$

We define $K^{*}$ as the value of $K$ solving (7.4a). Note that any value of $p$ along $K=K^{*}$ is an equilibrium, since $d K / d t=0$ when $K=K^{*}$ (net income of capitalists is zero).

The dynamics are easy to describe and are also depicted in Figure 1.3: To the right of $K=K^{*}, p$ is decreasing (the net return to capital is negative) and to the left it is increasing. Above the $d K / d t=0$ locus, but to the left of $K^{*}, K$ is decreasing, while above the $d K / d t=0$ locus, to the right of $K^{*}, K$ is increasing. Conversely, below the $d K / d t=0$ locus, but to the left of $K^{*}, K$ is increasing, while below the $d K / d t=0$ locus, to the right of $K^{*}, K$ is decreasing.

Let $p^{*} \equiv S K^{*} /(1-s)$. $K^{*}$ in combination of any value of $p<p^{*}$ is a stable equilibrium; $K^{*}$ and any value of $p \geq p^{*}$ is an unstable equilibrium. The saddle point trajectory $E E^{\star}$ divides the bottom quadrant (below $d K / d t=0$ and to the left 
of $K^{*}$ ) into a convergent and non-convergent region. Below $E E^{*}$, paths converge to $K=K^{*}$. Above $E E^{\star}$, they diverge. As a trajectory below the $d K / d t$ locus and to the left of $K^{*}$ approaches $K^{*}$, the slope is

$$
\frac{d p}{d K} \approx \frac{p}{s K-(1-s) p}
$$

which is finite below the locus $p=s K /(1-s)$. Hence, trajectories hit the vertical axis, at which point they remain in the steady state. We can similarly show that if $K_{0}>K^{*}, K$ will also hit $K$; but if the initial value of $p>s K /(1-s), K$ will initially increase, before decreasing to $K^{*}$.

Thus, there are an infinity of stable equilibria, in all of which the level of income is the same, but in which there can be markedly different values of wealth $(K+p T), p T$ is in this sense fully indeterminate. But if $K<K^{\star}$ and the initial price is too high, the economy experiences a bubble.

A generalized savings function. These results are partly a consequence of the special savings function employed. More generally, we assume

$$
\frac{d K}{d t}+\frac{d p}{d t}=s\left(K, p, \frac{d p}{d t}\right)
$$

Net savings are a function of capital, the value of land, and capital gains. $K$ and $p$ affect savings both because they increase the income and wealth of the individual. This formulation recognizes, however, that aggregate savings may differ depending on the composition of wealth (i.e. it is not necessarily just a function of $K+p T$, aggregate wealth). This may be because the risk properties of these assets differ or the individuals who own these assets differ.

With this formulation, the dynamics are described by (7.1) and

$$
\frac{d K}{d t}=s\left(K, p, \frac{d p}{d t}\right)-\frac{d p}{d t}=s\left(K, p, p\left(F_{K}-\mu\right)\right)-p\left(F_{K}-\mu\right)
$$

There are two possible (sets of) steady states. One is given by the solution to (7.4a) and ${ }^{98}$

$$
s\left(K^{*}, p^{*}, 0\right)=0 \text {. }
$$

If we assume (at $d p / d t=0$ ), $s_{K}>0$ and $s_{p}>0$ (in the absence of capital gains, an increase in wealth of any form leads to increased savings), then (at least near $K=K^{*}$ ) the $d K / d t=0$ is downward sloping. The dynamics are unstable (Figure 1.4a), and may be oscillatory, as illustrated in Figure 1.4b. ${ }^{99}$ Even though the local dynamics are unstable, there may be a limit cycle. In particular, 


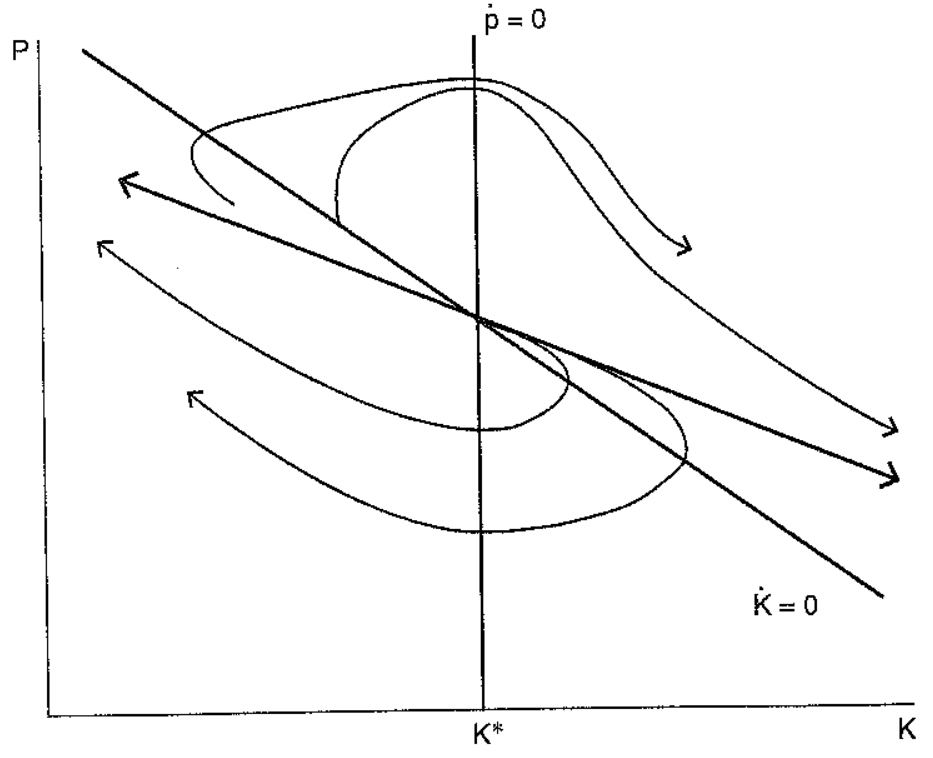

Figure 1.4a Unstable dynamics with non-productive land and non-linear savings function

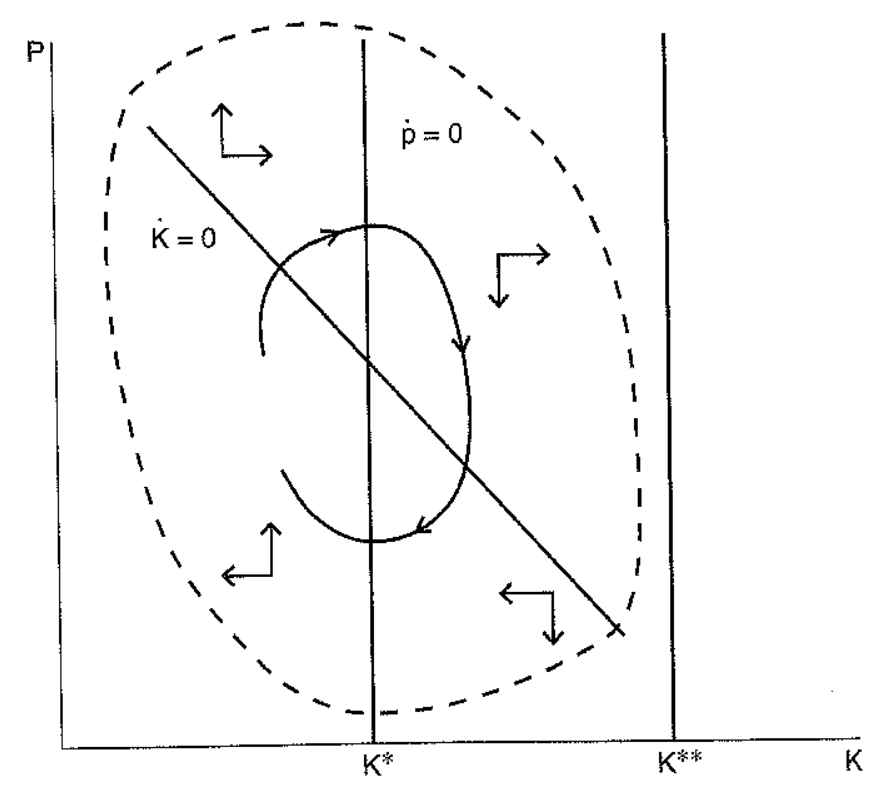

Figure $1.4 b$ Oscillatory dynamics with non-productive land and non-linear sayings function 
if the $\left.\frac{d p}{d K}\right|_{\frac{d K}{d t}=0}$ locus hits the vertical axis, then the dynamics are constrained.

$0 \leq K \leq K^{\star *}$ where $K^{* *}$ is defined by $f\left(K^{* *}\right)=\mu K^{\star *}$ (i.e. the capital stock that would result if the savings rate were unity.) $p$ is non-negative. We can trace out a single oscillation along the path that begins say at $K=K^{*}$ and $p$ very small. Such a path cannot hit the $K^{* *}$ boundary or the horizontal axis. If the value of $\mathrm{p}$ when it returns to $K^{*}$ is lower than the initial $p$, then subsequent oscillations are arbitratily close to the initial oscillation. If the value of $p$ when it returns to $K^{*}$ is greater than the initial $p$, all paths must be contained within the bound defined by this oscillation, a straightforward implication of which is that there must be a limit cycle. ${ }^{100}$

The second possible steady state is defined by $p=0$ and $s\left(K^{* * *}, 0,0\right)=0$. (Recall that $\frac{d p}{d t}=p\left(F_{K}-\mu\right)$ so that $\frac{d p}{d t}=0$ for $p=0$ for all finite values of $F_{K}-\mu$.) If $s_{k}>0$, so long as $p$ is constrained to be zero, the dynamics are stable. But if $p$ is ever perturbed above zero, the dynamics described earlier become applicable.

\subsubsection{Land-augmenting technological change}

In this section, we assume that land is productive and the effective land supply increases at the rate $n$. The equation describing the equalization of returns to land and capital now takes on the form

$$
\frac{d p}{d t}=p F_{K}-F_{T}
$$

In steady state, $\frac{d}{d t}(\log p)=n$.

Because the rate of land-augmenting technical progress is $n$, one unit of land becomes more valuable over time at the rate $n$. We define

$$
q=e^{n t} p
$$

so that

$$
\frac{d}{d t}(\log q)=\frac{d}{d t}(\log p)-n=F_{K}-\frac{F_{T} e^{-n t}}{q}-n
$$

Redefining units so that $T^{\wedge}$ is a unit of effective land, and denoting (as before) as output per unit effective labor, $f_{T^{\wedge}}=F_{T^{\wedge}}=F_{T} e^{-n t}$. Then the capital arbitrage equation can be rewritten

$$
\frac{d}{d t}(\log q)=\frac{d}{d t}(\log p)-n=f_{k}-\frac{f_{T^{n}}}{q}-n
$$


In steady state, $\frac{d}{d t}(\log q)=0$, so $f_{k}-n=\frac{f_{T^{\wedge}}}{q}$,

Or

$$
q=\frac{f_{T^{\wedge}}}{f_{k}-n}
$$

To simplify our analysis, for the remainder of this section we assume $\mu=0$ and we assume that a constant fraction of all income (including capital gains) is saved. We can write (7.2) as

$$
\frac{d}{d t}(\log K)+\frac{p T}{K} \frac{d}{d t}(\log p)=s\left(\frac{F(K, L, T)}{K}+\frac{T}{K} \frac{d p}{d t}\right)
$$

or in our normalized units

$$
\frac{d}{d t}(\log k)=s \frac{f(k)}{k}-\frac{(1-s)\left(q f_{k}-f_{T^{n}}\right)}{k}-n
$$

The steady state is given by the solution to the loci along which $d q / d t=0$ and $d k / d t=0$, given respectively by ${ }^{101}$

$$
q=\frac{f_{T^{\wedge}}}{f_{k}-n}=\Phi(k), k<k^{* *} \equiv f_{k}^{-1}(n)
$$

and

$$
q=\frac{s f(k)+(1-s) f_{T^{\wedge}}-n k}{(1-s) f_{k}} \equiv \psi(\mathrm{k})
$$

$\Phi^{\prime}>0$ provided only that

$$
\frac{F_{T K}}{F_{T}}>\frac{F_{K K}}{F_{K}}
$$

Under natural restrictions, the limit of $\Phi$ as $k$ goes to zero is zero, and as $k$ goes to $k^{* *}$ is infinity. In Figure 1.5 , we have drawn the curve as upward sloping. ${ }^{102}$ Above the curve, $q$ is increasing; below it is decreasing.

$\psi(0)=0$ under natural restrictions. Again, under natural restrictions, for large enough $k$, the numerator of (7.16) becomes negative. Define $k^{\star *}$ as the solution to ${ }^{103}$ 


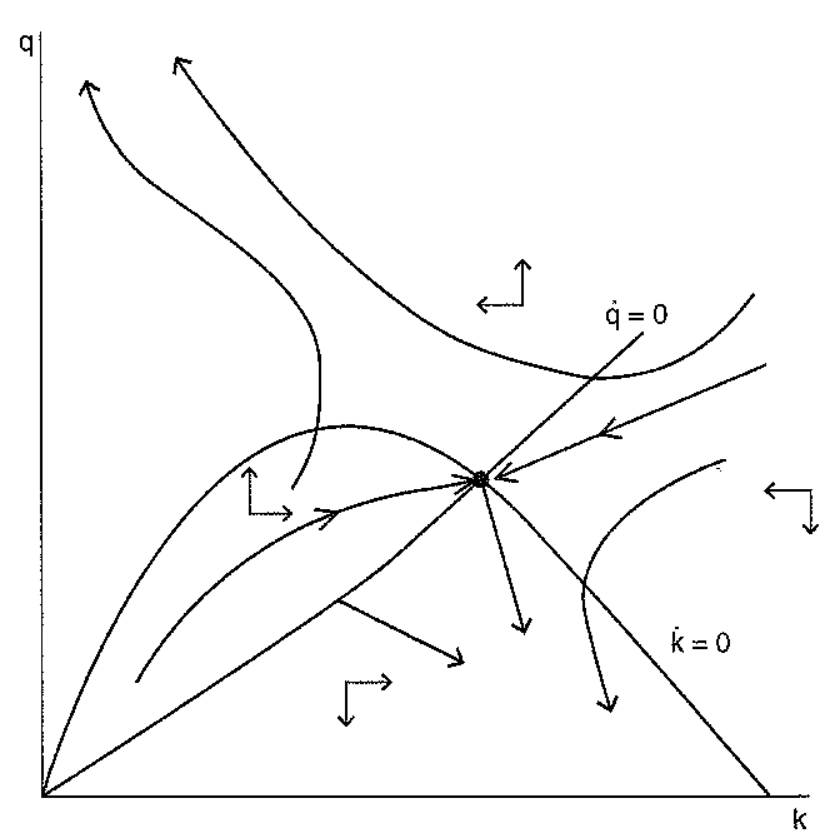

Figure 1.5 Steady state and unstable dynamics with land-augmenting technical change

Hence $\psi$ is the inverted $U$ shaped locus depicted in Figure 1.5. It is easy to show that the $\Phi$ locus cuts the $\psi$ locus from below and there is a unique equilibrium. Above the locus, $d k / d t$ is negative, below it is positive.

If land prices are too high, for ownership of land to generate the same returns as capital, the price of land has to increase. On the other hand, if $q$ is above both the $d k / d t=0$ locus and the $d p / d t=0$ locus, it means that the increase in the value of land ("savings" in this sense) acts as a substitute for real capital accumulation, and $k$ accordingly diminishes. The result is that the steady state equilibrium is a saddle point, as depicted in the figure.

With futures markets extending infinitely far into the future, $q$ is set along the trajectory converging to the steady state, that is, there is a unique value of $q$ for each $k$ such that the economy converges to the steady state.

Without futures markets extending infinitely far into the future or infinite foresight, there is no reason to believe that the transversality condition will be satisfied. But along the paths which satisfy the short run arbitrage equation but do not converge to the long run equilibrium because the initial price is too high, the price of land eventually increases super exponentially. ${ }^{104}$ As a result, in finite time, the "bubble" will be "corrected." But it can be a long time. And even when there is a "correction," it may still be on a "bubble path." The price of land falls, but to a level still above the convergent path. 
Note that on the trajectories in which the price of land "explodes," eventually the increase in the value of land crowds out capital accumulation - the capital stock declines, even though wealth continues to increase. Indeed, as $\mathrm{k}$ gets small, virtually all of wealth is in the value of land, and thus wealth increases at the rate of $n+\frac{d}{d t}(\log q)=n+f_{k}-\frac{f_{T^{\wedge}}}{q}$. Above the $d q / d t=0$ locus, $q f_{k}>f_{T^{\wedge}}$ so that wealth is unambiguously increasing (and even increasing per capita). Indeed the wealth-income ratio (as usually defined, where income ignores capital gains) goes off to infinity.

Taxation. We now ask, what happens when we impose taxation on capital gains and/or the returns to land. The capital arbitrage equation now becomes

$$
\left(1-t^{c y}\right) \frac{d p}{d t}=p F_{K}-F_{T}\left(1-t^{L}\right)
$$

In steady state, the price of land is going up at the rate $n$, so in the steady state (using our normalized units)

$$
\left(1-t^{(s)}\right) n q=q f_{k}-f_{T^{\wedge}}\left(1-t^{2}\right)
$$

Or

$$
q=\frac{f_{T^{\wedge}}\left(1-t^{L}\right)}{f_{k}-\left(1-t^{c g}\right) n}
$$

To complete the analysis, we need to specify what is done with the revenues raised by the tax. Assume that they are entirely spent on consumption. Then the capital accumulation equation becomes

$$
\frac{d}{d t}(\log k)=s \frac{f(k)}{k}-\frac{(1-s)\left(1-t^{c g}\right)\left(q f_{k}-\left(1-t^{L}\right) f_{T^{\wedge}}\right)}{k}-n
$$

so in steady state

$$
q=\frac{\left.s f(k)-n k+(1-s)\left(1-t^{L}\right)\left(1-t^{c g}\right) f_{T^{\wedge}}\right)}{f_{k}(1-s) n\left(1-t^{c g}\right)}
$$

The steady state is given by the solution to $\left(7.13^{\prime}\right)$ and $\left(7.16^{\prime}\right)$, giving the locus of $d q / d t=0$ and $d k / d t=0$ with land and capital gains taxes. From (7.13') the land tax lowers the $d q / d t=0$ locus, but leaves the $d k / d t=0$ locus unchanged. As Figure 1.6a shows, this means that an increase in a tax on the return to land leads to an increase in the capital-labor ratio and an increase in wages, 
validating the common presumption that savings diverted into land investment (or speculation) is money that could otherwise have gone into real investment.

A tax on capital gains shifts both curves upwards, and as Figure $1.6 \mathrm{~b}$ shows, the consequence is again that the equilibrium capital-labor ratio increases. (The effect on the price of land is more ambiguous in the case of a tax on capital gains; along the $d k / d t=0$ curve, at any $k$, a higher tax on capital gains has to be offset by a high price of land, and by itself this would have implied a higher equilibrium $q$. But at the same time, this is partially offset by the shift downward of the $d q / d t=0$ locus. $)^{105}$

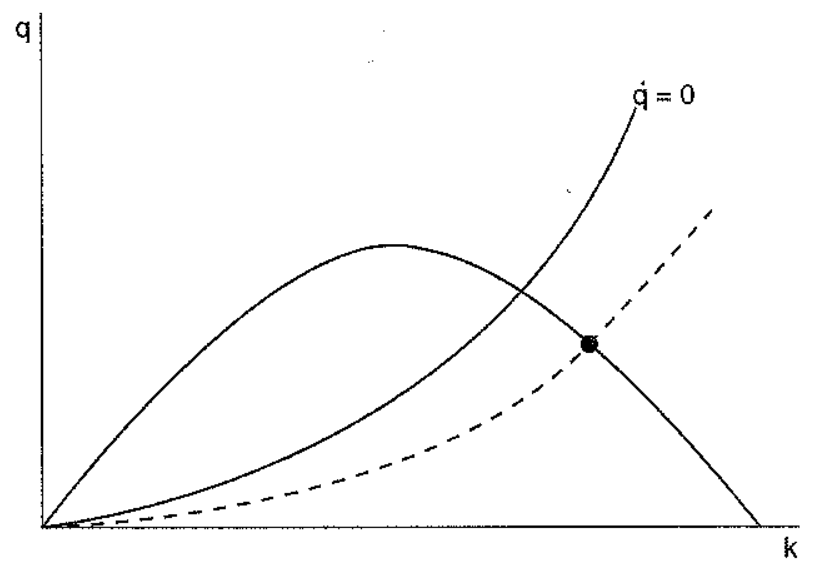

Figure 1.6a Effect of increase in tax on returns to land

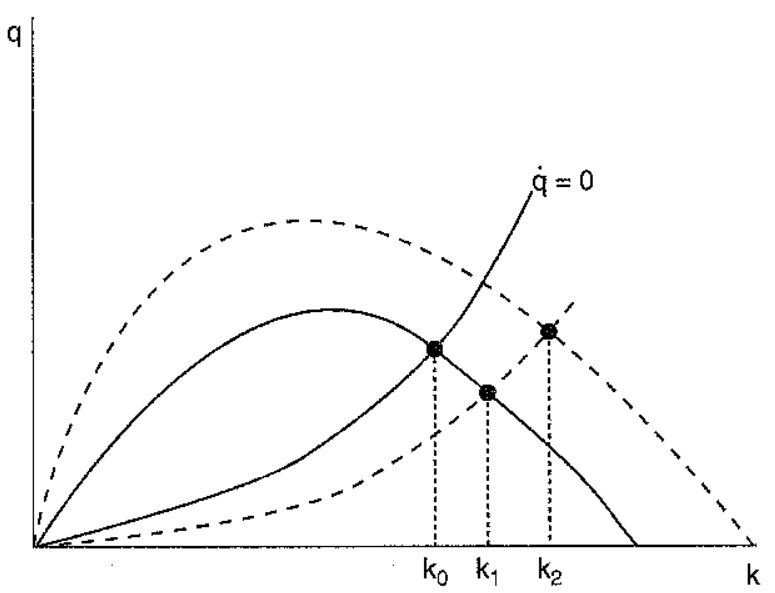

Figure 1.6b Effect of tax on capital gains 
On the other hand, if the revenues are spent on investment, then

$$
\frac{d k}{d t}=s f(k)-(1-s)\left(1-t^{c g}\right) q n+t^{c g} q n+t^{L} f_{T^{\wedge}}-n k
$$

or in steady state

$$
q=\frac{s f(k)-n k+t^{L} f_{r^{\wedge}}}{n(1-s)\left(1-t^{g g}\right)-n t^{c g}}
$$

Relative to the previous equilibrium, the $d k / d t=0$ curve is shifted up even more (while the $d q / d t=0$ curve is unchanged), so that the equilibrium value of $k$ is increased even more.

\subsection{Credit, collateral, and wealth inequality}

We have argued that much of the growth of wealth is associated with the increased value of land and other fixed assets. Land, and certain other assets, have one attribute which makes them particularly attractive: they can be $\mu$ sed as collateral. The fact that they can be used as collateral may increase their value; but the value associated with the ability to be used as collateral will depend on the financial system. If, for instance, banks do no lending based on collateral, then the "collateral value" will be zero; the easier access to credit for those who have collateral, the higher these assets will be valued.

Moreover, the demand for land and other assets depends itself on the availability of credit - a fact that was made abundantly clear by recent experiences with Quantitative Easing. (Indeed, one of the rationales for quantitative easing, and one of the main channels for its claimed success, was that it led to higher asset prices, with the hope that the increased wealth would in turn lead to more consumption.)

In this section, we suggest that the system by which credit is provided may be one of the main sources of wealth and income inequality: if a favored few get access to credit, then their wealth increases relative to those without such access. Nowhere was this clearer than in the former Soviet Union, where bank licenses were granted to some politically connected individuals. The access to funds that this provided enabled them to acquire state assets as they were being privatized; the limited access to funds meant that competition was limited and they could acquire the state assets at far below fair market value.

In a less dramatic way, wealth inequality in the United States and other advanced countries may also be linked with the financial system. If much of the growth of wealth is related to an increase in credit (or other changes 
in the financial system); if access to credit is based on collateral; and if the assets which have benefited from the increase in credit (or other changes in the financial system) are disproportionately owned by the rich, then it should be apparent that these increases in credit and other changes in the financial system may have played a major role in the increase in wealth and income inequality.

Our system of credit creation may perversely create not only inequality at the top, but also at the bottom. It persuades the poor to borrow beyond their ability, and then charges them usurious interest rates. Changes in bankruptcy laws making it ever harder to discharge debts create a system of partial indebted servitude. Struggling to survive, they have no ability to make investments that would help them emerge from such poverty, and indeed, even to think long term. In the models below, we ignore these effects, focusing on the link between credit, collateral, land, and capital accumulation.

\subsubsection{Credit and the value of land as a positional good}

In this section, we provide a bare-bones model that we think may capture more accurately what has been going on than any of the models presented so far: the banking system provides credit based on collateral. When the price of land in the Riviera goes up, the banks are willing to lend more. If the banks are willing to lend more, the price of land in the Riviera goes up. There is, essentially, an indeterminacy: it is the decision of the banks (the central bank) concerning credit availability that drives the price of land (real estate).

We modify the model of section 2 by assuming three distinct classes of individuals - workers who just consume, capitalists who save out of profits, own enterprises and invest only in capital goods, but have no access to credit and rentiers, who own land. ${ }^{106}$ Their demand for positional good (land in the Riviera) is given by $M\left(W^{T}, c, p\right)$, with the equilibrium condition now being given by

$$
M\left(W^{T}, c, p\right)=p T=W^{T}+c,
$$

where $c$ is the amount of credit that is available and $W^{T}$ is the wealth of the rentier, which is just the value of the land minus what they owe in credit: $W^{T}=p T-c$. Substituting into $(8.1)$ we obtain

$$
M\left(W^{T}, c, \frac{W^{T}+c}{T}\right)=W^{T}+c
$$

We can solve for 
The wealth of the rentiers is entirely driven by the provision of credit

$$
W^{T}=p T-c=T \psi(c)-c
$$

To close the model, we need an additional equation describing capital accumulation. We take the simplest version, due to Kaldor (1957). ${ }^{107}$ Capitalistsentrepreneurs save a fraction of their income, $s_{p}$, putting their money into capital goods

$$
\frac{d K}{d t}=s_{p} r K-\mu K
$$

where $\mu$ is the depreciation rate, so in steady state

$$
F_{K}\left(K^{*}, L\right)=\frac{\mu}{S_{p}} .
$$

In this model, the provision of additional credit has no effect on the equilibrium capital stock. We thus obtain from $\left(8.1^{\prime}\right)$, letting $W=W^{T}+K$, the sum of the wealth of the rentiers and the capitalists,

$$
\frac{d W}{d c}=\frac{d W^{T}}{d c}=\frac{-\left(1-M_{c}-M_{p} / T\right)}{1-M_{W^{T}}-M_{p} / T}
$$

An increase in credit increases wealth through an increase in land prices, but has no effect on the capital stock. Since it is only the wealthy who own the land and that get access to credit, all of the increase in wealth (capital gain) goes to the wealthy. Monetary policy causes both the increase in (nonproductive) wealth and the increase in wealth inequality. But while wealth has increased, wages are unaffected. Note that in this model, since credit simply leads to asset price increases (and an increase in the price only of the fixed asset land) - but not commodity price increases - there is no reason that a monetary authority focusing on commodity price inflation would circumscribe credit creation.

\subsubsection{Credit and the creation of land bubbles and inequality}

In this section, we consider a simple extension of the model of section 3 to incorporate credit, with land-augmenting technological progress at the rate $n$. To simplify, we assume that land and capital goods are perfect substitutes for each other, that there is no consumption value to land, and there are not two separate classes of entrepreneurs and rentiers. Land and capital are simply 
alternative stores of value, and in equilibrium they must yield the same return. Then, as before,

$$
\frac{d}{d t}(\log q)+\frac{f_{r^{n}}}{q}=f_{k}-n
$$

Moreover, the full income of capitalists is now $F_{K}(p T+K)$, so that capital accumulation is described by (as before, letting $T^{\wedge}$ denote the effective land per worker, which is fixed, and assuming for simplicity that $\mu=0$ )

$$
\frac{d k}{d t}+T^{\wedge}\left(q f_{k}-f_{T^{\wedge}}\right)=s_{p}\left(f_{k}\left(T^{\wedge}+k\right)+T^{\wedge}\left(q f_{k}-f_{T^{\wedge}}\right)\right)-n .
$$

As before, (8.7) and (8.8) describe the full dynamics of the economy in terms of $\{q, k\}$.

Now assume, however, that the banking system ${ }^{108}$ only provides credit with land as collateral, but provides it at zero interest rate, so that owners of land borrow as much as they can. The central bank limits the amount of credit that is made available. As more credit is provided, the price of land will be bid up, and in equilibrium

$$
c=\alpha p T
$$

where $\alpha$ reflects the collateral requirement. If $\alpha$ is fixed,

$$
\frac{d}{d t}(\log p)=\frac{d}{d t}(\log c)
$$

Or

$$
\frac{d}{d t}(\log q)=\frac{d}{d t}(\log c)-n
$$

There is a path of expansion of the credit supply which ensures that (8.8) is satisfied. If the financial system expands credit supply at a pace that is faster than that implied by (8.8) and (8.10), the return to land will exceed the return to capital. In this polar model, if this were anticipated, no one would want to hold capital. The price of capital goods would fall below 1 , and the production of capital would halt. $k$ would decrease with the increase in the population. We then replace 8.7 with

$$
\frac{d}{d t}(\log q)+\frac{f_{T^{\wedge}}}{q}=\frac{f_{k}}{z}+\operatorname{dlog} z / d t
$$


where $z$ is the price of capital goods in terms of consumption goods; and

$$
\frac{d}{d t}(\log k)=-n
$$

$k$ decreases and $q$ increases. ${ }^{109}$ If $c$ increases fast enough, the value of wealth increases, and even wealth per capita increases, even though the capital stock per capita is decreasing.

Note that along such a trajectory the ratio of the (full) income of capitalists to that of workers will be increasing, provided that the elasticity of substitution is not too low (with the critical value being greater than one).

$$
\frac{Y_{K}}{Y_{L}}=\frac{F_{K}(p T+K)}{F_{L} L} .
$$

where $Y_{K}$ is the (full) income of capital and $Y_{L}$ that of labor. Note too that while the value of wealth is increasing, the return to capital will be increasing and that to labor decreasing. Hence trajectories where there is a rapid expansion of credit shift the income distribution towards capitalists. Of course, on such trajectories, growth in output will be low, in spite of the rapid increase in wealth. This simple model is consistent with the stylized facts described in Part I of this paper. (Note that while the ratio of full income of capitalists to that of workers is increasing, the ratio of income in the national income accounts to that of workers will be decreasing if the elasticity of substitution is less than one. $)^{110}$

In more general models, where there is not a linear production possibilities frontier, an increase in credit leading to an increase in the value of land can initially lead to more investment, but eventually an increasing proportion of savings is absorbed by increases in the value of land, and, as here - and evidently as in many countries - the rate of real capital accumulation diminishes.

\subsubsection{Credit creation, monetary policy, and inequality}

To see more precisely how the "rules of the game" on credit creation can affect the distribution of wealth, first consider the model of the previous subsection, where credit is provided at a low rate against land as collateral. The return to holding land $\rho_{T}$ is then the capital gain on land, the yield on land, and the option that owning land provides to get access to capital at a low rate: ${ }^{111}$

$$
\rho_{T}=(1+a) F_{K}=(1+a)\left(\frac{d}{d t}(\log p)+\frac{F_{T}}{p}\right)
$$

where here owning a dollar's worth of land allows one to borrow enough to increase one's land holdings to $(1+\alpha)$, on each unit of which one obtains 
a return equal to the return on capital. In equilibrium, the return to land must equal the return to capital, and this means that if there is a change in the rules of the game - say a lowering of the collateral required for a loan - then there will be an increase in the price of land: those who are lucky enough to own land at that moment receive a large capital gain. ${ }^{112}$ Such a change could be motivated by an improvement in the ability to manage risk, or by political influence, with the financial industry persuading politicians that such a change would allow a more efficient capital market. Of course, such a change in the regulations regarding lending does not increase the amount of real resources available in the economy, even if it might allow banks to lend more, and thereby might increase the profitability of banking. ${ }^{113}$

A slight variation of the life cycle model of Part III allows us to explore in more detail some of the distributive consequences of such a change or similarly, of a change in monetary policy that resulted in lower lending rates. Here, we investigate these issues in a highly stylized model that provides insights into the natural reasons that the ownership of land or other assets that might be used for collateral should be concentrated at the top. The issues can be seen more clearly in the context of a model where we assume only two factors of production, capital and labor, and that the ownership of capital ("equity in capital") can be used for collateral.

Assume that workers are very risk averse, while the wealthier capitalists are (close to) risk neutral. We assume that the government issues a fixed number of bonds B; each bond pays a fixed (real) interest rate, $r_{g}$ which is controlled by the government (monetary authority). We assume that the returns to capital are variable, so that all the capital is owned by the capitalists (they are the owners of equity), and all government bonds are owned by workers. Again, for simplicity, we assume that capitalists save and reinvest all of their gross income.The price of the bond is $\pi$. Thus the real rate of return to holding a bond is $\frac{r_{g}}{\pi}$. Because of risk aversion, $\frac{r_{g}}{\pi}$ can be substantially below $E\left(F_{K}\right)$, the expected return on capital, and workers will still hold their wealth in government bonds. On the other hand, so long as $r_{g} / \pi$ is less than $E\left(F_{K}\right)$ no capitalist will hold a government bond. The price of the bond adjusts so that all of workers' savings is held in bonds, ${ }^{114}$ i.e. assuming a constant savings rate of $s$ out of wages (net of taxes). If workers pay no taxes, then

$$
B \pi=s w
$$

Interest on government bonds is financed through taxation. Not surprisingly, the structure of taxation matters.

Assume for simplicity that interest payments to workers are financed through a lump-sum tax $\tau$ on workers, i.e. $r_{g} B=\tau$. It can be shown that 
equilibrium requires $\pi=1,115$ i.e. $B=\frac{s w}{1+s r_{g}}$. Now, a change in $r_{g}$ financed by a tax on labor leaves the returns to capital unchanged, ${ }^{116}$ and that means that $K^{*}$ is unchanged and $w$ is unchanged; but it necessitates a change in $B$ and $\tau$. In particular, it can be shown that an increase in $r_{g}$ leads to an increase in $\tau .{ }^{117}$ It thus leads to decreased first period consumption, but to increased second period consumption. ${ }^{118}$ Since across steady states, $C_{1}+C_{2}=w$, the steady-state utility of workers is maximized at $r_{g}=0$ (when in effect individuals face the same constraint). ${ }^{119}$

In this model, the $\mathrm{T}$ bill rate is totally divorced from the rate-of return on capital. We can, however, link the two, by assuming that the government, while borrowing from workers (who are engaged in life-cycle savings), is willing to lend to capitalists at a rate that is equal to or greater than that rate. For simplicity, we assume that there is a single rate, but that the government rations the amount it is willing to lend to capitalists, since so long as $r_{g}<F_{K}$, risk-neutral capitalists will want to borrow as much as possible. The way it rations credit is to require collateral. Hence, if a unit of capital allows a firm to borrow $\alpha$, the overall return to a dollar of accumulation is $F_{K}(1+\alpha)-\alpha r_{g}$.

In the short run, a lowering of $r_{g}$ leads to an increase in the net income of capitalists by an amount proportional to $\alpha K^{*}$ and a reduction of the income of life-cycle savers/workers by a corresponding amount. It is, in effect, a direct transfer from workers (life cycle savers) to capitalists.

Note that in this model, the distributive consequences of a lowering of the interest rate are the opposite of that derived in conventional "class" analysis, where workers are seen as debtors and capitalists as creditors. In that model, a lowering of the interest rate hurts capitalists and helps workers. Here, workers and capitalists are both owners of capital, but different kinds of capital. A lowering of the interest rate helps owners of equity and hurts those who hold government debt. This model seems to be a better description of the modern economy, and in this model, lowering interest rates unambiguously contributes to growing inequality. (This model, however, abstracts from Keynesian aggregate demand effects, which are the central motivation in lowering interest rates. We have assumed a full employment neoclassical economy.)

Over the long run, with $\alpha$ fixed, a lowering of $r_{g}$ increases the return to investing, implying a higher equilibrium value of $K,{ }^{120}$ and a higher wage rate, from which workers gain. The long-run equilibrium condition is (continuing with our simplifying assumption of $s_{p}=1$ )

$$
F_{K}(1+\alpha)-\alpha r_{g}=n
$$

Moreover, as $r_{g}$ is lowered, they gain also from the lowering of $\tau$. But once $r$ is lowered below zero, there is an offsetting distortion in the intertemporal 
pattern of consumption. This means that there is (from workers' long run welfare perspective) an optimal $r_{g}<0 .{ }^{121}$

Inequality in wealth is given by $s w / K$; and it is possible to describe how this changes with a change in $r_{g}{ }^{122}$ For very large elasticities of substitution, the increase in $K$ has little effect on $w$, so inequality increases; while for small elasticities of demand, the increase in $K$ increases wages significantly, and reduces inequality.

Who gets the rents associated with credit creation? The essential insight of this analysis is that differences between life cycle savers and capitalists affect the asset composition of their holdings, and this means that policy changes (tax, monetary, and regulatory policies) affecting the relative returns and prices of different assets have differential effects on the two groups.

A natural question is, can't the process of credit allocation be changed to ensure that the rents associated with access to credit that are effectively being given the owners of capital through credit creation are more fairly shared? Why not have an auction of credit, so there won't be any rents?

Part of the answer is provided by the theory of information asymmetries: Stiglitz-Weiss (1981) and a large subsequent literature have explained why the provision of credit cannot be auctioned. There has to be an allocation process, entailing judgments about who is most likely to repay. But if that is the case, then who controls the allocation process makes a difference. Because it is a difficult task, entailing difficult judgments, it is natural that it be entrusted to those who are better educated, to the elites. But the elites are better judging those that are similar to themselves; there is an additional element of risk in judging those that are different. Moreover, there are shared judgments about risks and values. Not surprisingly, then, they allocate capital to those that are similar to themselves - even when and where connected lending is prohibited; and, of course, even more so when connected lending is allowed. In this manner, inequality builds on itself.

But that doesn't mean that there aren't excessive rents built into the financial system, and not just through the abuses that have been especially well-documented in the aftermath of the 2008 crisis, based on market exploitation (see, for example, Stiglitz, 2010). Consider, for instance, the allocation of credit for mortgages. Today, such allocation is not based on judgment so much as credit scoring. It is an information intensive process, involving the processing of information about the incomes of the borrower and the values of the properties being acquired. But government entities have the best data, and the government is in the best position to enforce the debt contract: the government, through the income tax system, has a complete history of income, and through property registries, of real estate transaction prices. The incremental cost of collecting mortgage payments through the income tax system is negligible. Indeed, it could easily construct a system of income contingent mortgage loans that 
would be far better than the current system. ${ }^{123}$ Administrative costs for such a system are likely to be very low, so that mortgages could be provided at an interest rate only slightly greater than that paid on government debt. The huge rents (and the associated instability and inequality) of the private mortgage system could be greatly reduced, and the enormous waste of resources as financial institutions look for fools upon whom they can prey would also be reduced.

\subsection{Concluding remarks}

This paper has attempted to explain key stylized facts about changes in macroeconomic variables, including those describing changes in the distribution of income and wealth, within models in which there is micro- and macroconsistency. Among the key findings are:

- Standard data on savings cannot be reconciled with the increase in the wealth-income ratio: there is a wealth residual. That is, observed increases in wealth and wealth-income ratios cannot be explained by the steady process of the accumulation of capital.

- An important component of the "wealth residual" is associated with an increase in rents: land rents, exploitation rents - including those associated with information asymmetries, monopoly and other forms of market power - and returns on intellectual property. Any theory attempting to explain the evolution of the economy must thus focus on explaining the increase in rents and their capitalized value, which are an increasingly important share of overall wealth.

- Concepts of "capital" and "wealth" are distinct. Appropriately defined aggregates for the inputs into production and wealth may be move in opposite directions. The productive capacity of the economy may thus not increase in tandem with measured wealth. Indeed, in many economies (including the US), productive capacity may be falling even as wealth is increasing. An increase in the market value of land does not make the economy more productive. An increase in wealth as a result of increased monopoly power, or political power which transfers resources from the public to corporations (for example, through corporate welfare) may even reduce the productive capacities of the economy.

- This resolves some long-standing paradoxes; the fundamental law of diminishing returns says that an increase in wealth should lead to a lowering of the return to capital. But, in fact, because real wealth - what might be called "real capital" or "productive capital" - has not increased in tandem with measured wealth, there is no necessity that the return to capital would fall as measured wealth increases.

- Similarly, we would expect an increase in wealth to be associated with an increase in average wages. This would be true even with technological 
change (even if it is "skill-biased") or if there is a change in the composition of the labor force. The large gap that has opened up between the growth in appropriately measured average wages and productivity is consistent with the hypothesis that there has been an increase in market power.

- The increase in market power and other forms of exploitation rents can be in part explained by changes in technology and changes in institutional, legal, and economic structures.

- The paper provides several models (including life cycle models where land is a store of value or is a positional good) to explain why land values typically increase as wealth and wealth inequality increase: the wedge between wealth and real capital increases.

- The economy is dynamically unstable; that is, it is prone to the kinds of bubbles that have marked the economy in recent years. Particularly on such bubble paths, the increase in land values (wealth held in the form of land) crowds out real productive investment. Thus, the poor performance of the American economy - when employment, the growth of output, wages, median wealth and income, and other indicators are considered - should not come as a surprise.

In short, this paper gives the theoretical underpinnings explaining why, in recent decades, wages have stagnated while GDP and productivity have continued to grow. It explains not only wage stagnation, but also credit-fueled bubbles. There has not been growth in productive capital relative to GDP (especially when controlling for increases in the value of real estate). The growth in wealth is for the most part simply the growth in the capitalized value of rents. This growth in rents has a negative effect on societal wellbeing.

The paper also has explored key determinants in wealth distribution, focusing in particular on the distribution between life cycle savers and "capitalists." A marked change in the structure of the economy over the last 75 years has been the increase in life-cycle savings. We derive a simple formula describing the relative share of inherited wealth:

$$
\frac{k^{w * *}}{k^{*}}=n \frac{s\left(k^{*}\right)}{s_{p}} \frac{1-S_{k}}{S_{k}}
$$

(where $\mathrm{n}$ is the rate of growth, $\mathrm{s}\left(\mathrm{k}^{*}\right)$ is the savings rate of workers, and $\mathrm{s}_{\mathrm{p}}$ that of capitalists, and $S_{k}$ the share of capital): In general, the wealth and income of capitalists will not continually increase relative to the rest of the economy, though in moving from one equilibrium to another, there can be marked increases. The magnitude of wealth inequality does not in general depend on the difference between the rate of return on capital or the rate of interest $(r)$ and the rate of growth. The rate of return on capital is an endogenous variable, and needs to be related to underlying parameters of behavior and 
technology (which the above formula does.) The analysis also notes that workers' savings does not (in this model) lead to higher wages or incomes per capita, but simply crowds out capitalists' savings. Introducing land into the standard neoclassical life cycle model lowers the equilibrium share of workers' wealth: wealth holdings in the form of land crowd out, in effect, productive savings.

We have also noted the ability of the financial system to exploit life-cycle savers, by lowering the return they receive on their assets relative to those received by the wealthy; this naturally decreases the share of wealth owned by life-cycle savers.

We have suggested, moreover, that there may be no fundamental difference between capitalists and workers: they may have the same savings function, with differences in savings rate simply reflecting differences in their wealth. It is not because workers save little that they have little wealth to pass on to their children; it is because they have little inherited wealth that they have a low savings. History matters: there can exist different steady states, depending on initial conditions.

In related work (Stiglitz, 2015), we have analyzed the distribution of wealth among capitalists. ${ }^{124}$ The wealth distribution is the result of a balancing out of centrifugal and centripetal forces, forces pulling the economy apart and bringing it together. Increases in inequality can be attributed to the strengthening of centrifugal forces and the weakening of centripetal forces. Examples of strengthened centrifugal forces include the lowering of taxes at the top, the spending of more on the education of the children of the rich than of the poor, and increased dispersion of the returns to capital. An example of a weakening of centripetal forces is the weakening of public education. We are able to derive a simple formula describing the level of inequality in wealth among the very rich (the Pareto coefficient). It is related to the share of capital, the level of taxation of capital, and the degree of progressivity (or regressivity) of capital taxation. Again, because the return to capital is endogenous, the degree of inequality in the long-run equilibrium is not related to the difference between the growth of the economy and the return to capital. Moreover, just as the increase in wealth cannot be explained within the standard economic model, neither can the increase in wealth inequality. Once again, it is changes in policies, not economics, that are driving what is happening.

Our analysis provides a number of insights into how policies can affect inequality:

- Policies that reduce rents and their capitalized value can reduce inequality and increase economic performance. Efficiency and equity imply that rents should be taxed at very high rates; and taxes on capital with appropriate loss offset provisions actually encourage risk taking. 
- Capital taxation has to be carefully designed to avoid problems of shifting (where before-tax returns increase, so that after-tax returns are not lowered). Progressive capital taxation with proceeds at least partially spent on public investments can reduce inequality and increase national output.

- A land (real estate) tax and a tax on natural resources - a generalized Henry George tax - can succeed not only in reducing inequality but can also lead to higher national output. (Since investments in land crowd out real investment, the lowered value of land as a result of taxation crowds in real investment.)

- Given the large amount of life-cycle savings, the traditional division of society into the owners of capital and workers or creditors and debtors may no longer provide the most insights for understanding the impact of policies on distribution. The relevant division is between capitalists, who pass on their wealth from generation to generation, and workers, who save for their retirement, and between the owners of equity and the holders of debt instruments. Since the wealthy are disproportionately the holders of equity, a lowering of interest rates (as in quantitative easing) benefits them but hurts holders of government bonds, disproportionately life-cycle savers, and thus increases inequality.

- We show the links between the increases in land values, monetary policies, and the structure and conduct of the financial system, demonstrating how changes in the rules governing that sector and the conduct of monetary authorities may increase inequality. A lowering of collateral requirements or of banks' capital adequacy requirements does not result in an increase in the overall efficiency of the economy, but leads to more inequality. ${ }^{125}$

In short, a tax on rents can raise revenue, not only incentivizing more productive investment, but also ensuring that more of society's scarce savings go into such productive investments, thereby enhancing growth and reducing inequality.

The deficiencies of the neoclassical model in explaining inequality that we have noted should make us wary about using that model for policy purposes either for addressing inequality or for broader issues of economic performance. That model cannot account well for changes in inequality; we cannot explain these changes solely in terms of changes in the underlying key parameters that have traditionally been the focus of attention, related to technology and behavior, such as savings rates, bequest behavior, and reproduction rates, and the differences among families with respect to these variables.

For more than two centuries, there has been an attempt to break away from a feudal system in which a child's position in society is preordained by that of his parent, and to move to a meritocratic system where it is determined by the child's own ability. In many respects we have succeeded, but perhaps not as much as we had hoped: the evidence is that even in a society like the United States avowedly 
committed to meritocracy, inherited advantages play a key role, and more than a role than can be explained by the process of transmission of genes.

We should be concerned with wealth inequality, however it is generatted, because societies in which there are large wealth (and income) inequalities function differently from more equalitarian societies. There are social and political consequences. It is worth noting that the attack on monopolies and trusts in the Progressive era was more motivated by concerns about their political and social consequences than the market distortions to which they gave rise.

Because so much of the increase in inequality in income and wealth is related to changes in policies, changes in those policies may be able to ameliorate this growing inequality. If we believe that there are large costs to our economy, our democracies, and our societies from this growing inequality, then at the very least, we should ask, are there changes in policy which will slow down this increase in inequality - and perhaps reverse it. An understanding of the forces that may be contributing to the growing inequality, such as that we have attempted to provide here, is a first step in constructing such a policy agenda.

In fact, a long list of policy changes - changes in legal frameworks, taxes, and expenditures - which would lead to less inequality in both the short run and the long which might do this, and simultaneously increase economic performance, has already been identified. ${ }^{126}$ It is not the lack of knowledge that is preventing these actions from being undertaken. It is politics, a politics shaped by inequality of political power which follows from and can amplify inequalities in economic power. ${ }^{127}$ The growing inequality in our society is thus a reflection as much of democracy in the twenty-first century as it is of capitalism in the twenty-first century.

The fact that inequality is not just, or perhaps even mostly, the result of inexorable economic forces but of policies should be a source of hope: for it holds out the possibility that alternative policies might change the directions in which advanced economies seem to be heading. And it makes all the more imperative the research agenda to which this paper hopefully has made a contribution, of trying to understand better the determinants of the equilibrium wealth and income distribution.

\section{Appendix A: Proof that average wages should increase with} capital deepening

Assume $Y=F\left(K, L_{1}, L_{2}, \ldots\right)$ is constant returns to scale. In the following discussion, we will simplify and assume only two types of labor. Constant returns to scale (CRTS) implies that

$$
F_{L_{1}} L_{1}+F_{L_{2}} L_{2}+F_{K} K=F
$$




$$
F_{L_{1}, K} L_{1}+F_{L_{2}, K} L_{2}+F_{K K} K=0,
$$

Diminishing returns implies $F_{K K}<0$, which is why if there is only one type of labor $F_{U K}>0$ : an increase in capital must increase the marginal productivity of labor, so that an increase in capital (relative to labor) must increase the wage. Here, it is clear that the wage of one of the two types of labor could go down.

But consider the average wage, $\bar{w}$ :

$$
\bar{W}(K)=\left(F_{L_{1}} L_{1}+F_{L_{2}} L_{2}\right) / L
$$

where $L=L_{1}+L_{2}$.

$$
\bar{w}^{\prime}(K)=\frac{\left(F_{L_{1}, K} L_{1}+F_{L_{2}, K} L_{2}\right)}{L}=-\frac{F_{K K} K}{L}>0 .
$$

The weighted average wage must increase when capital (the capital labor ratio) is increased. This result is strengthened if we assume that there is an increase in the quality of the labor force. Let $\omega$ be the proportion of high skilled workers. ${ }^{128}$ Then

$$
\frac{d \ddot{w}}{d t}=\bar{w}_{K} \frac{d K}{d t}+\left(F_{t_{1}}-F_{L_{2}}\right) \frac{d \omega}{d t}>0
$$

\section{Appendix B: Relationship between change in wealth} and aggregate inputs

Consider the rate of change of wealth, $W=K+p T$ :

$$
\frac{d \log (W)}{d t}=\xi \frac{d \log (K)}{d t}+(1-\xi) \frac{d \log (p)}{d t}
$$

where it will be recalled

$$
\xi=K / W
$$

But

$$
p=[(1-\zeta) / \zeta] K / T,
$$

so, substituting into (B.2), we obtain $\xi \equiv \zeta$ so that

$$
\frac{d}{d t}(\log (C))=s / \beta
$$

and

$$
\frac{d}{d t}\left(\log \left(\frac{C}{Y}\right)\right)=\frac{s}{\beta}-g
$$


Moreover,

$$
\frac{d \log (p)}{d t}=\frac{d \log (K)}{d t}
$$

Hence

$$
\frac{d \log (W)}{d t}=\frac{d \log (K)}{d t}
$$

\section{Appendix C: Inheritance taxes}

In this appendix, we analyze the effects of taxing only the return on inherited wealth. Life cycle savings is exempted, e.g. through IRA accounts. Now, we have a somewhat more complicated problem than that analyzed in the tax. Tax revenues are given by

$$
\mathrm{T}=\tau^{c} r\left(\mathrm{k}^{*}\right)\left(k^{*}-k^{* * *}\right)
$$

where

$$
k^{* *}=s\left(k^{*}\right)\left(w\left(k^{*}\right)+\mathrm{T}\right)
$$

Substituting (C.1) into (C.2), we obtain

$$
k^{w *}=\frac{s\left(k^{*}\right)\left(w\left(k^{*}\right)+\tau^{c} f^{\prime}\left(k^{*}\right) k^{*}\right)}{1+s\left(k^{*}\right) \tau^{c} f^{\prime}\left(k^{*}\right)}
$$

We have already shown that as $\tau^{c}$ increases $w\left(k^{*}\right)+\tau^{c} f^{\prime}\left(k^{*}\right)$ decreases. Similarly, as $\tau^{\iota}$ increases the denominator increases. Hence, so long as $s^{\prime} \geq 0, k^{w *}$ decreases. $k^{*}$ decreases. If the elasticity of substitution is greater than a critical threshold (less than unity), the share of life-cycle wealth increases; but if the elasticity of substitution is very small, it can decrease because of tax shifting. ${ }^{129}$

Now, however, the effect on relative consumption (wellbeing) is more ambiguous. In particular, at $\tau^{c}=0$, using (3.11)

$$
\frac{d Y^{w}}{d \tau^{c}}=\frac{d w}{d k^{*}} \frac{d k^{*}}{d \tau^{c}}+r\left(k^{*}\right)\left(k^{*}-k^{w *}\right)=-k^{w *} f^{\prime}\left(k^{*}\right)<0
$$

On the other hand, since $r\left(k^{*}\right)=f^{\prime}\left(k^{*}\right)=\frac{1}{s_{p}\left(1-\tau^{c}\right)}, \frac{d r}{d \tau^{c}}=\frac{r}{1-\tau^{c}}$. Workers' lifetime utility if a function of their income and the return to capital: $V\left(r(k), Y^{m}\right)$, where $V$ is the indirect utility function. ${ }^{130}$ Hence $^{131}$ at $\tau^{\mathrm{c}}=0$,

$$
\frac{d V}{d \tau^{c}}=\frac{\partial V}{\partial Y^{W}}\left[k^{w *} f^{\prime}\left(k^{*}\right)+\left(-k^{w *} f^{\prime}\left(k^{*}\right)\right]=0\right.
$$

That is, the loss in income is precisely offset by the increased retum to capital. But for $\tau^{c}=0$, the interest rate effect is larger, and initially the transfers are larger, and workers' 
utility is increased, even though wages are lower. But as $\tau^{c}$ increases, eventually $\mathrm{k}^{*}$ falls below $\mathrm{k}^{* \mathrm{w}}$ : the economy switches to a one class economy, with only life cycle savings, with

$$
s\left(k^{w *}\right) w\left(k^{w *}\right)=\frac{k^{w *}}{1+n} .
$$

Clearly, because wages are lower than they were in the initial equilibrium and there are no transfers, workers' incomes are lower. There exists an optimal inheritance tax $\tau^{\star \star}, 0<\tau^{\star \star}<1.132$

\section{Notes}

1. University Professor, Columbia University. This is a revised version of a paper originally presented at an IEA/World Bank Roundtable on Shared Prosperity, Jordan, June 10-11, 2014 and at an INET seminar at Columbia University, December 3, 2014. I am grateful for the helpful comments of the participants in the roundtable and seminar, and in particular, to the discussants, Duncan Foley, Paul Krugman, and Banko. Milanovich.

The issues discussed in section 2 of this paper on the measurement of wealth and capital were discussed at a special session of the IEA World Congress, Amman, sponsored by the OECD on the Measurement of Wellbeing, and at a meeting sponsored by the OECD High Level Expert Group on the Measurement of Economic Performance and Social Progress, Rome, September 2014. I am indebted to Martin Durand, Chief Statistician of the OECD, and other participants at those meetings for their helpful comments and insights into the key issues of the measurement of wealth and capital, and in particular to Baul Schreyer, both for his insights and for supplying me with the data cited in section 2. I am also indebted to Martin Guzman, Arjun Jaradayev, Suresh Naidu, Stefano Battiston, and Mauro Gallegati for their comments. I have also benefited from conversations with Adair Turner and Shahe Emran. My earlier work in this area was greatly influenced by Tony Atkinson, David Bevan, John Flemming, Robert Solow, James Meade, Frank Hahn, Nicholas Kaldor, Jim Mirrlees, Benoit Mandelbrot, and David Champernowne. Financial support was provided by INET (the Institute for New Economic Thinking) and the Ford Foundation Inequality Project at Roosevelt Institute. I am indebted to Feiran Zhang, Ruoke Yang and Eamon Kircher Allen for research assistance.

2. Kaldor (1961). For a recent review of the attempts to explain these facts, see Jones and Romer (2009).

3. This paper focuses on advanced countries. A slightly different analysis would be required for developing and emerging countries, though the theoretical formulations presented here are general.

4. These are not the only stylized facts that need to be explained. There is a large literature trying to explain the shape of the income and wealth distribution, for example, why the tails of the distribution are Pareto (fat-tailed), and why at lower levels of income, the income distribution seems to be described by a lognormal distribution (Aitchison and Brown, 1957; Lebergott, 1959). These are addressed in Stiglitz (2015b).

5. Reflected not just in growing Gini coefficients, but an increasing share of income going to those at the very top. Given that inequality in each of the components of 
income (wages and the return to capital) is increasing, and the relative importance of the more unequal component, capital, is also increasing, it is, of course, obvious that there would be an inctease in overall level of income inequality. See, for example, OECD (2011) and Piketty (2014).

6. Real US wages have stagnated for decades (see Shierholz and Mishel, 2013). Adjusted for inflation, average hourly earnings of production and non-supervisory employees have decreased some 30 percent since 1990 . See St. Louis Fed data at http://research. stlouisfed.org/fred2/series/AHETPI/. More dramatic, while the labor share may have decreased from the mid 80 percent in the 1970 s to less than 80 percent by 2009 , the aggregate labor share excluding the top 1 percent compensation (whose returns, as we note below, often consists significantly of what can be referred to as rents) has slid from just under 80 percent to around 60 percent. See Giovannoni (2015).

7. See Piketty (2014) and Piketty and Zucman (2014). For the UK, Germany, and France, the wealth-income ratio rose from about 300-360 percent in 1970 to $377-618$ percent in 2010 . The US had a relatively small increase, from 399 percent to 456 percent.

8. Kuznets (1955)

9. Piketty also says that, among those who hold wealth, "the distribution of wealth tends toward a long-run equilibrium and that the equilibrium level of inequality is an increasing function of the gap $r-g$ between the rate of return on capital and the growth rate ... The greater the difference $r-g$, the more powerful the divergent force. If the demographic and economic shocks take a multiplicative form (i.e., the greater the initial capital, the greater the effect of a good or bad investment), the long-run equilibrium distribution is a Pareto distribution (a mathematical form based on a power law, which corresponds fairly well to distributions observed in practice). One can also show fairly easily that the coefficient of the Pareto distribution (which measures the degree of inequality) is a steeply increasing function of the difference $r-g . "$ (Piketty, 2014, pp. 363-4). We examine these hypotheses in Stiglitz (2015b), showing that the qualitative propositions are not, in general, valid.

10. Roberts (2014). It appears that Piketty's analysis seems to have overestimated " $r$ ", overestimated the extent to which returns were reinvested, and underestimated the importance of the division of wealth among one's heirs.

11. Piketty himself recognizes the possibility that there can be an increase in the value of land, but quickly dismisses its historical importance (though he notes that does not mean that its importance might rise in the future): "... the increase in the value of pure land does not seem to explain much of the historical rebound of the capital/ income ratio (sic)" (p. 198).

12. Included in the increase in the value of land is the value of artificially created scarcity, e.g. through zoning requirements. Land rents are likely to go up significantly with increasing urban aggiomerations-it is not, as Piketty (2014) seems to suggest, that rents some places go up, and others go down. For instance, in a simple model of the city, Arnott and Stiglitz (1979) show that land rents go up with aggregate transport costs. Not surprisingly, the importance of agglomerations increases with the size of local public goods. (In their highly idealized model, they obtain the result that with cities of optimal size, differential land rents are equal to the expenditures on local public goods, and are one half the value of aggregate transport costs.)

13. A result that is consistent with the findings of Galbraith (2012).

14. See, for example, Stiglitz $(1966,1969)$.

15. At least for some countries, there appears to be an increase in inherited inequality relative to life cycie inequality Bowles and Gintis (2002) and Piketty (2014). But 
there is not unanimity about this conclusion. See, in particular, for the US, Wolff and Gittleman (2011). Our model enables us to ascertain the conditions under which either result might be expected.

16. As we shall note below, what really matters is the growth of the effective labor force, the sum of the labor force growth rate and the rate of labor augmenting change.

17. It is worth noting that in standard models, the condition $r \geq g$ must be satisfied if the economy is intertemporally efficient. If Piketty's analysis were correct, it would imply that, except in the limiting case where $\mathrm{r}=\mathrm{g}$, any efficient economy would be characterized by ever increasing inequality.

It is also worth noting that in the special parameterization so loved by macroeconomists, the Cobb-Douglas production function, average and marginal returns move in tandem, so that a fall in the average productivity of capital would be accompanied by an equiproportionate fall in the marginal productivity. In the case of an elasticity of substitution less than unity, the fall in the marginal productivity is larger. (See the discussion below.)

18. More precisely, as we will explain below, in the effective-capital labor ratio, taking into account the increased productivity of each worker.

19. There are still other anomalies about which we will have only a little to say in this paper. Globalization was supposed to increase societal welfare for all countries; even if there were distributional effects within countries, the gainers could more than compensate the losers. There is increasing evidence that there are indeed losers (Acemoglu et al., 2014); but the losers are being told that they must accept further cutbacks in wages and government services in order for the country to compete, seemingly suggesting that globalization requires them to accept a lower standard of living.

20. See Arrow et al. (1961); Young (2013). It should be noted that some authors have recently argued otherwise. See, for example, Mallick (2007).

21. The net private savings rate for the US over the period 1970-2010 has been 7.7 percent (Piketty and Zucman, 2014). As they point out, most of the variability in wealth income ratios (at least as conventionally measured) can be attributed to the private sector.

22. This can be expressed in another way. The average annual increase in the capital stock for the US they estimate to be 3.0 percent, of which the average "real" savings accounts (by the calculation above) to about 1.5 percent, or just half. (Piketty and Zucman (2014) suggest that savings accounts for 72 percent of the increase in the wealth-income ratio.)

23. We obtain similar results if we postulate particular behavioral models. Take a simplified version of the model that seems to underlay Piketty's analysis, a Kaldorian savings model (Kaldor, 1957), where capitalists save a fraction $s_{p}$ of their income and workers nothing. Piketty (2014) implicitly seems to assume $s_{p}=1$, but the overwhelming evidence is that even the very rich save a much smaller fraction of their income than that. Saez and Zucman (2014) estimate that the average saving rate for the wealthiest 1 percent of Americans was 36 percent from 1986 to 2012. Similarly, Dynan et al. (2004) obtain high savings rates for the rich - but far lower than unity. For simplicity; assume the after-tax rate of return on capital (it should be obvious that what matters is after tax returns) is 5 percent, $s_{p}=4$. Then capital would increase at the rate of $.05 \times .4=.02$. If the growth rate were greater than 2 percent, the private capital-output ratio would be declining. Note that if the share of capital is around .2 , this generates a national savings rate of 8 percent, just slightly higher than the actual private savings rate. 
Similar results hold if there are some savings out of wages. As Pasinetti (1962) notes, a more reasonable model divides income according to whom it accrues, i.e. interest and wage income accruing to workers is treated similarly. In Part III of this paper, we assume workers save for their retirement, while capitalists save to pass on money to their heirs. In Part III, we sketch a model in which the division of society into these different groups arises endogenously.

24. It is obvious, of course, that the short run fluctuations in the wealth-income ratio are dominated by capital gains and by cyclical movements in income. The marked changes in the wealth-income ratio in the US before and after 2008 highlight these points.

25. In the Kaldorian model, the long-run capitalmoutput ratio is given by $s_{f} S_{K} / g^{*}$, where $S_{K}$ is the share of capital.

26. For instance, between 1960 and 2000, the savings rate fell from 8 percent to 2 percent while the rate of growth increased from 2.3 percent to 4.1 percent. If these were permanent changes, then the long run capital-output ratio would have fallen by a factor of almost 8 . (Actually observed growth rates will be higher than $g^{*}$ - the sum of the rate of growth of population and labor augmenting technological progress - if there has been capital deepening, less than $g^{*}$ if the teverse has been happening.

27. Matters are no better if we view the savings rate as endogenous, determined by intertemporal utility maximization. Then, the critical variable is the intertemporal discount rate, and again, it is hard to see changes in that variable of the magnitude that would account for changes in the observed capital-output ratio.

28. For wage data see Shierholz and Mishel (2013).

29. That is, Giovannoni (2014) noted that between 1980 and 1990 the share of the bottom 99 percent of workers has gone down by over 20 percent, which means that the ratio of their average wage to their average productivity has gone down by the same amount. More dramatic results are observed if we look at broad categories of workers like production and non-supervisory workers, where (real) wages have stagnated over the past forty years, while average productivity has doubled. Note that with the Cobb-Douglas production function much beloved by macro-economists, marginal and average productivities move perfectly together. Note too that skillbiased technological change might explain why there might be marked disparities in movements in median wages and average productivity; but it does not explain the phenomenon just described.

30. The first to propose the idea of skill-biased technological change was Griliches (1969). See also Krusell et al. (2000), Autor (2002); and Autor, Katz, and Kearney (2008).

31. See Card and DiNardo (2002) and Shierholz, Mishel, and Schmitt (2013) and the references cited there.

32. Interpretations of Piketty's work, which confuse the increase of "wealth" with an increase in capital argue that there must be an elasticity of substitution greater than unity - how else could one explain the rising share of capital. But if the elasticity of substitution is greater than unity, then labor augmenting technological change would lead to an increase in wages at a fixed capital stock, and an even larger increase in wages were the capital stock to increase. (The elasticity of substitution has to be substantially below unity for the wage to decrease. If there are different kinds of labor, similar results hold for the average wage.)

33. Labor augmenting technological change leads to a higher return to capital, and the presumption is that it would lead to higher investment. This would lead to a still higher wage. 
34. For simplicity, assume that only the productivity of skilled workers (denoted with subscript 1) increased. Let $\lambda=$ the productivity of a skilled worker. If $\frac{d F_{K}}{d t}=0$, $F_{K K} \frac{d K}{d t}+F_{1, K} \lambda L_{1} \frac{d \log (\lambda)}{d t}=0$, and normalizing $L$ at unity, $\frac{d \bar{w}}{d t}=\left(F_{1, K} \lambda L_{1}+F_{2, K} L_{2}\right) \frac{d K}{d t}$ $+\left(F_{1,1} \lambda L_{1}+F_{2,1} L_{2}\right) \lambda L_{1} \frac{d \log (\lambda)}{d t}+F_{1} L_{1} \lambda \frac{d \log (\lambda)}{d t}$. Using the properties of constant returns to scale production functions and the condition that $\mathrm{F}_{\mathrm{K}}$ is unchanged, we can show that $\frac{d \bar{w}}{d t}=F_{1} L_{1} \lambda \frac{d \log (\lambda)}{d t}>0$.

35. The analysis of capital-augmenting technological progress is somewhat more complicated. First, the "volume" measure of the capital stock discussed below is supposed to adjust for differences in quality of capital. Whether it does so adequately is beyond the scope of this paper. Secondly, with capital augmenting technological progress, there is no steady state. Short-term capital augmenting progress, by increasing the effective capital stock, would have been expected to have an unambiguously positive effect on wages.

36. These problems are similar to those that have arisen in the measurement of poverty, with Pogge and Reddy (2010) arguing that standard estimates do not adequately reflect differences in prices faced by the poor - a claim that Martin Ravallon has disputed, illustrating that these index number problems are both difficult and contentious.

See, in particular, the discussion of positional goods later in this paper

37. I am very indebted to Paul Schreyer of the OECD, who concludes his discussion of these issues (personal note to author) by observing "the distinction between the wealth and production aspects of capital is indeed important and a story about ' $W$ ' does not immediately translate into a story about ' $K$ '. Associated with the two perspectives are different measures that evolve quite differently. However, the key aspect in the analysis of capital in production and its link to income shares seems to be the treatment of non-produced assets, in particular land."

38. As we noted earlier, aithough land is not very important in most industrial processes (certainly not as important as it is in agriculture), housing services represent an important component of GDP, and land is an important input into real estate.

39. We note that this is not a plausible production function, since if that were the case, there shouldn't be any changes in the relative price of $T$ and $K$, since they are perfect substitutes.

40. Similar results hold for the two other countries for which we have been able to obtain comparable data, Australia and Korea, from the OECD. Land accounts for a large part of national wealth - at current prices, between 40 and 60 percent - and the wealth-output ratio excluding land has been rising, while the ratio including land has been falling. I am indebted to Paul Schreyer for these data.

41. See Stiglitz $(2003,2010 a)$ and the references cited there.

42. Indeed as Giovannoni (2014) points out, simply excluding the top 1 percent of wage earners results in a very large decline of the wage share between the period from around 1980 to 2009 , from slightly more than 75 percent to around 60 percent.

43. Some question the magnitude of some of the increase in inequality, say the share of income at the top for the US, because of changes in the tax law in 1986 which may have led to a change in reported income, not actual incomes earned. (Feldstein, 2014) We should note that the studies of inequality looking at the increased inequality at the top have attempted to deal with this obvious problem. (Piketty and Saez, 2003). 
But the pattern of increased inequality (an increased share of total income going to the top 1 percent) continued even after tax changes were partially reversed in 1993. Moreover, other countries without corresponding changes in tax codes have seen similat increases in inequality. (Interestingly, because in the US, the top is the only part of distribution that has done very well, if it were the case that most of their seeming increase in income is just a change in reporting, it would imply that that the overall performance of economy has been really dismal; one would have to explain how it is that, given all of the increase in wealth, all of the "improvements" in economic policy, and all of the alleged gains from globalization and technology, all of these together seem to have generated so little improvement in standards of living to any group in our society, not even, allegedly, the very top.)

It is, of course, plausible that the overall level of inequality at the top is greater than that reported. Administrative data show reported (realized) capital gains, but the tax system provides strong incentives for those at the top not to realize their capital gains.

44. In the short run, there can be capital gains on producible assets as well, but such increases cannot be sustained in the long run, since they will elicit a supply response. Some of the increase in "seeming" wealth that occurred in the US prior to the 2008 crisis may have been attributable to capital gains on buildings (though it is difficult to parse out such capital gains from capital gains on land). But the "correction" brought down the implied price of building to or below the reproduction cost. If we take consumption goods as our numeraire, the price of capital goods could increase or decrease, though such changes typically are of a limited magnitude in the absence of technological change; with technological change, there can, of course, be significant changes in appropriately measured prices.

45. Itself an endogenous variable. Changes in preferences and technology can lead to increased agglomerations, with an increase in land values.

46. See Knoll, Schularick, and Steger $(2014,2015)$.

47. Hotelling (1931) showed that if the cost of extraction of a depletable natural resource were zero, its price would rise at the rate of interest (which in an efficient equilibrium is always greater than or equal to the rate of growth.)

48. Piketty, Saez, and Stantcheva (2014) provide an interesting empirical test, pointing out that increases in tax rates at the very top are not associated with siower rates of growth. See Stiglitz (2012a, 2014b) for a broader discussion, including the many forms that rent-seeking takes in a modern economy, and other evidence that rents have become an important source of income at the very top.

49. The timing of increases in the share of capital are perhaps more consistent with those being explained by rapid changes in the degree of exploitation than by sudden changes in the effective capital labor ratio. Similarly, it is hard to reconcile the enormous divergence between average compensation and productivity of workers without assuming an increase in market power. (See Giovannoni, 2014.)

50. Assume, for instance, that $\mathrm{W} / \mathrm{Y}=4$. Assume the increase in rents are capitalized in the stock market. Then $\Delta W=.05 Y / .015$, so if $Y$ is unchanged, $\Delta(W / Y)=3.33$, so now $\mathrm{W} / \mathrm{Y}=7.333$. Actually, the increase in the wealth-income ratio is even greater than these calculations would suggest, since, as we note in the next paragraph, the distortion in the economy lowers the magnitude of the denominator.

51. See, for instance, Federal Reserve Board (2015) for a discussion of the cost to consumers of predatory lending practices.

52. Indeed, the extensive research on efficient markets has questioned the value-added of the wealth management services of the financial sector: ordinary investors would have done as well or better simply by buying indexed funds. 
53. Stiglitz (2012a) outlines many other forms of rent seeking. Some forms of rentseeking may detract from measured wealth. If CEOs are able and willing to take greater advantage of deficiencies in corporate governance laws to appropriate for themselves more of the value of corporations, that should lead to a decrease in the market value of firms. There is, however, considerable evidence that because of the lack of transparency of the manner in which they appropriate these returns, markets typically do not fully reflect the dilution in shareholder value. Moreover, much of the compensation takes the form simply of a transfer of ownership claims on the returns to the firm. Note further that if this rent appropriation by managers is labeled as "compensation," then the wage share is increased. This is consistent with the results noted earlier suggesting a marked decline in the wage share if the upper one percent of "wage earners" are excluded.

54. This discussion raises similar issues as those the Commission on the Measurement of Economic Performance and Social Progress discussed in moving economic activities from the public to the private sector (see Stiglitz et al., 2010),

55. See, for example, Stigltiz (1975)

56. See, for instance, Henry and Stiglitz (2010) and the works cited there.

57. As we note below, such changes are often accompanied by a loss in wellbeing of others: they must now make royalty payments to the owner of this intellectual property. But the diminution of their wellbeing is not necessarily reflected symmetrically in the wealth accounts. Moreover, the charges imposed for the use of knowledge lower GDP, and thus a change in the intellectual property regime extending rights to enclose the knowledge commons can both increase the measured value of wealth and lower the value of GDP: the wealth-income ratio will accordingly rise.

The privatization of public knowledge or the granting of "excessive" intellectual property (patents that are excessively broad, such as covering all four-wheeled self-propelled vehicles, or copyrights that are excessively long, such as extending 70 years beyond the death of the writer) can be viewed as a special case of the exploitation rents discussed above.

There is one more form of rents associated with intellectual property that has almost surely grown over time: that generated by brand names, especially the identification of a product with say a sports star).

58. See Sraffa (1960) and Stiglitz (1974). Thus, in models with the production of commodities by means of commodities, the economy at a low interest rate and a high interest rate may look the same (the same technologies are employed), while at an intermediate interest rate a different technology is employed. Even if the value of wealth has changed in going from the low to the high interest rate, there has not been capital deepening, at least in any meaningtul real sense. There are a variety of other reasons that there can be changes in intertemporal pricing, with large consequences to the valuation of assets. See the discussion below.

59. While financial markets often claim that their innovations have enhanced the ability to manage risk, the extent to which this is the case remains debated. Some of the financial innovations may have actually increased risk (Stiglitz, 2010b). Some of the financial innovations may have led to the creation of pseudo-wealth - wealth based simply on differences in perceptions in beliefs (Guzman and Stiglitz (2014)); while other innovations, like improvements in the ability to sell short, may reduce market values (Scheinkman and Xiong, 2003). Part IV of this paper will show how changes in financial market regulations can affect the value of assets.

60. See Milevsky and Huang (2011). For statistics on the size of pension funds, see OECD (2013). 
61. In that sense, the model is similar to that of Pasinetti (1962), where there are two classes too. We model workers' saving (life cycle savings).

62. $S_{p}$ can be derived endogenously, if, as in the standard representative agent model, families maximize dynastic utility.

63. Notice that for capitalists, savings are defined as the addition to their wealth, while for workers, since each worker starts life (in this model) with no wealth, savings are their total wealth. (There are alternative formulations based on gross savings generating similar results.)

64. We could have employed a more general savings function: $S\left(k_{t}, k_{t+1}\right)$ where the savings rate depends not only on the rate of return on capital (which depends on $k_{t+1}$ ) but also on wages, which depend on $k_{t}$. It should be apparent that in the steady state, savings is just a function of $k$. Little here depends on the precise form of $s$, though we will observe that some results do depend on whether savings increase or decrease with $k_{t}$. Note that an increase in $k$ will be associated with an increase in wages and a decrease in interest rates. $s$ will increase with $k$ so long as the substitution effect of the decreased wages is not too large.

65. As Stiglitz (2010b) shows, there can in general be an infinite number of trajectories consistent with rational expectations. This follows from the fact that there may be more than one solution to (3.1) and (3.2) and (3.3) for $k_{t+1}^{w}$ for any $k_{t}$ (Substituting (3.1) into (3.2), we obtain $\left.k_{t+1}^{H}=s\left(k_{t+1}^{H+}+B\left(1+s_{p} f^{\prime}\left(k_{t}\right)\right) k_{t}^{c} /(1+n)\right) w\left(k_{t}\right)\right)$. The reason is that if workers expect a high interest rate, they will need to save little for their retirement - but then the interest rate will be high; but if they expect a low interest rate, they will need to save a lot, but then the interest rate will be low.

66. If workers' intertemporal utility functions are Cobb-Douglas, then $s^{\prime}=0$. If workers utility function is such that $U=\min \left\{C_{t}, C_{t+1}\right\}$, then $(1-s) w=s(1+r) w$, or $s=1 /[2+r]$, so (3.7) can be rewritten $\frac{k^{n *}}{k^{*}}=n \frac{1}{2 s_{p}+n} \frac{1-S_{k}}{S_{k}}$. An increase in $s_{p}$ reduces the share of inherited wealth provided the elasticity of substitution is not too small.

67. As we have noted earlier, there are a number of other factors that could affect life cycle savings - the adequacy of provision of health care for old age, the efficiency of annuity markets and the extent to which they are affected by asymmetries of information, and uncertainties both about retirement age, rates of return to capital, and life expectancies. In practice, there are other institutional factors: most individuais save through retirement programs, and the rules and regulations concerning those retirement programs can have first order effects on the amount set aside. 68. The critical condition is that $s\left(k^{*}\right) w\left(k^{*}\right)<k^{*}$, or that $\frac{s\left(k^{*}\right)}{s_{p}}<\frac{S_{k}}{n\left(1-S_{k}\right)}$. If $n=1, S_{k}=0.2$,
then the condition becomes $s\left(k^{*}\right)<0.25 s_{p}$.

69. We should emphasize that this result is not general. In Part IV of this paper, we consider, for instance, a model in which capitalists have a choice of assets to hold and in equilibrium, they hold all of the risky assets. In a generalization of that model, it is easy to show that a tax on the excess returns to capital over the safe interest rate leads to more risk taking, i.e. a shift in their portfolio to higher return assets (Domar and Musgrave, 1944; Stiglitz, 1969b). If these assets are complements to labor, that shift by itself may increase wages. We note later too that taxes on capital gains in land may redirect investment into forms that are more complementary with labor.

70. From (3.4a) $\frac{f^{\prime \prime}(k) k}{f^{\prime}(k)} \frac{d \log (k)}{d t}=\frac{\tau^{c}}{1-\tau^{c}} \frac{d \log \left(\tau^{c}\right)}{d t}$ 
71. Since $s$ is fixed, and $Y^{w}$ falls, $k^{w *}$ falls, while $k^{*}$ increases. We can rewrite (3.7) with taxes as $\frac{k^{\text {m* }}}{k^{*}}=n \frac{s\left(k^{*}\right)}{S_{p}\left(1-\tau^{c}\right)}\left(\frac{1-S_{k}}{S_{k}}+\tau^{c}\right)$ where $S_{k}$ is the share of capital before tax.

72. If the government invested only a fraction $z$ of its revenues, then if $z$ is small enough $\left(<s_{p} r\left(1-\tau^{c} \equiv Z^{*}\right)\right.$, there is an equilibrium ratio of $\frac{K_{p}}{K_{g}}$ given by $\frac{s_{p}\left(1-\tau^{c}\right)-z}{\tau^{c} Z}$. where $K_{g}$ is the capital stock owned by the government, $K_{p}$ is that of the private sector. For $z<Z^{*}$, $k=f^{\prime \prime-1}\left(\frac{n}{s_{p}\left(1-\tau^{c}\right)}\right)$. For a fixed $\tau^{c}$, changes in $z$ have no effect on the wages received by workers. The payments from the government (per worker) are $(1-z) r\left(k-(1-\tau) k_{p}\right)$. We already noted that at the limiting case where $z=0$, workers are worse off than they would be without taxation.

73. That is, the equilibrium is described by the solution to the pair of equations (in the natural notation):

(i) $(1-\tau) s_{p} f_{k_{p}}=n$

(ii) $\frac{\tau^{c} f_{k_{p}} k_{p}}{k_{g}}+f_{k_{s}}=n$

74. An earlier version of the ideas in this section were delivered as a keynote address at the National Tax Association annual meetings, Santa Fe, November, 2014.

75. See Stiglitz (2015).

76. This is particularly relevant given the literature which has suggested that the pure returns to capital should be taxed at a zero rate, based on a misinterpretation of the Atkinson-Stiglitz (1976) result. See also Stiglitz (2015).

77. We cited evidence that that was the case earlier.

78. This particular formulation has the characteristic of a jump in the level of savings. A formulation with similar consequences is $s(W)=s_{0}$ for $W \leq W_{1} ; s(W) W=$ $\mathrm{s}_{0} \mathrm{~W}_{1}+\mathrm{s}_{1}\left(\mathrm{~W}-\mathrm{W}_{1}\right)$ for $\mathrm{W}_{1} \leq \mathrm{W} \leq \mathrm{W}_{2}$; and $\mathrm{s}(\mathrm{W}) \mathrm{W}=\mathrm{s}_{0} \mathrm{~W}_{1}+\mathrm{s}_{1}\left(\mathrm{~W}_{2}-\mathrm{W}_{1}\right)+\mathrm{s}_{2}\left(\mathrm{~W}-\mathrm{W}_{2}\right)$ for $W \geq W_{2}$, with $s_{1}>>s_{0}$ and $s_{1}>>s_{2}$.

79. In Stiglitz (2015b), we also suggest that that model also could not adequately explain the growth of wealth inequality that has been observed.

80. We also noted in Part I that there has been an increase in other forms of rents, and when capitalized, these too give rise to an increase in wealth

81. This results should be contrasted with that of Part III of this paper. The difference arises from the difference in the determinants of savings. We believe that the assumptions made here provide a better description of today's economy.

82. Arnott and Stiglitz (1978) and Stiglitz (2015c) have precisely calculated urban land values for cities of different geometries, relating it to aggregate transport costs and spending on local public goods.

83. The value of land is $\left(1-t^{L}\right) \frac{f_{r^{n}}}{f_{k}}$. The reduction in $f_{k}$ will normally partially offset the tax, so that the value of land will not go down commensurately with the reduction in $1-t^{2}$.

84. For a more complete analysis of this model, see Stiglitz (2010b). Similar results hold with money, rather than land, as we show in the Part IV of this paper.

85. The other interesting case is that where land as an unproductive store of value.

If $n=0$ and $s_{p}=1$, then in steady state, the interest rate will be zero, and the price of land will be constant. (4.6) takes on the form

$$
k_{t+1}+q_{t+1} T=k_{t}+q_{t} T \text {. }
$$


It should be clear that $k^{*}$ in combination with any value of $q$ is an equilibrium: as before, the value of land is indeterminate.

On the other hand, if $s_{p}<1$, the analysis of the steady state presents some problems. Assume that there were a steady state. $r^{*}$ will be positive, and that means that the price of land has to be ever increasing - but that in turn would imply that wealth is increasing and capital is an increasingly diminishing fraction of wealth. And who would hold this ever increasing wealth?

The only value of $q_{0}$ consistent with the equilibrium conditions is $q=0$. If $q$ were ever to be positive, for the capital arbitrage equation to be satisfied, an increasing fraction of savings has to be devoted to holding land, and a diminishing amount goes into capital accumulation. The rate of interest would, accordingly, rise. But as that happens, capital gains increase even more, diverting even more savings into land. In short, as before, the equilibrium (with $q=0$ ) is not stable.

86. If $R$ is the rent from the land, and $r$ is the real interest rate, then the value of land $V_{T}=R / r$, so that there is an equiproportionate increase in the value of land from a decrease in the real interest rate.

87. This analysis applies to a comparison across steady states with different $K$.

88. $p=M(W, p, u)$, and, assuming that expectations about capital gains are fixed, $\frac{\partial \mathrm{W}}{\partial \tau^{L}}=\frac{\partial \mathrm{p}}{\partial \tau^{L}}=\frac{p M_{u}}{1-M_{w}-M_{p}}$. A natural stability condition ensures that the denominator is positive. Since $M_{u}<0$, the tax reduces the price of land.

89. But there are important effects going the other way, and which almost surely predominate - for instance, the increased insecurity that the non-rich face, not adequately reflected in income statistics.

90. The increase in the price of land is only partially explained by the discussion of this section. Section 4 argues that the expansion of the credit supply provides an important part of the explanation.

91. The recurrence of bubbles has been noted by Kindleberger (1978)

92. Hahn (1966), Shell and Stiglitz (1967).

93. For simplicity, we assume that $\mathrm{F}_{\mathrm{K}}$ approaches infinity as $\mathrm{K}$ approaches zero, and that the marginal product of capital falls to zero only as $\mathrm{K}$ approaches infinity.

94. In the Kaldor model, $r=n / s$ where here, $\mathrm{s}$ is the savings rate of capitalists; in the Solow model, where everyone has the same rate, $r<f / k=n / s=0$. Similar results obtain in the two-class model of Part III of this paper.

95. See, e.g. Stiglitz (2014) and the references cited there.

96. Similar results hold for a model with money, such as that formulated in section 4.

97. Similar results can be obtained if we assume savings are a fixed fraction of overall income (including capital gains).

98. If $s_{p}>0$, there is a unique solution to (7.4a) and (7.8).

99. The dynamics are oscillatory if $\left(s_{K}\left(K^{*}, p^{*}, 0\right)-p^{*} F_{K X}\left(K^{*}\right)\right)^{2}<4\left(-s_{p}\left(K^{*}, p^{*}, 0\right) p^{*} F_{K K}\left(K^{*}\right)\right)$.

100. Note that $\left.\frac{d p}{d K}\right|_{\frac{d K}{d t}=0}=-\frac{s_{K}-p F_{K K}\left(1-s_{3}\right)}{s_{p}+\left(F_{K}-\mu\right) s_{3}}$. If as $K$ gets small, $s_{p}$ remains greater than $\left(1-s_{3}\right)\left(F_{K}-\mu\right)$, then the $\left.\frac{d p}{d K}\right|_{\frac{d K}{d t}=0}$ locus will hit the vertical axis. ( $s_{3}$ is the (marginal) savings out of capital gains. It is natural to assume that $0<s_{3}<1$.

Along any trajectory, $\frac{d p}{d K}=\frac{d p / d t}{d K / d t}=\frac{p\left(F_{K}-\mu\right)}{s-p\left(F_{K}-\mu\right)}$ which goes to zero as $p$ goes to zero. 
101. The steady state can also be described by the intersection of (7.13) and the locus $\frac{s f\left(k^{*}\right)-n k^{*}}{(1-s) n}=q^{*}$.

which gives the values of $k$ and $q$ such that $d k / d t=0$ when $\frac{d}{d t}(\log p)=n$.

102. A sufficient condition for this is that land and capital are complements.

103. If there is more than one solution, $k^{* *}$ is defined as the smallest.

104. When the price is too low, eventually, the price may shrink to zero. For the rest of the analysis, we ignore this case.

105. The sign depends on whether for the $d k / d t=0$ locus, $\frac{\partial k}{\partial\left(1-t^{t g}\right)}$, conditional on fixed $q$, is greater than for the $d q / d t=0$ locus, i.e. whether at $q^{*},(1-s)\left(f_{T^{\wedge} k}-q f_{k k}\right)$ is greater or less than $s f^{\prime}\left(k^{*}\right)-n$. Either seems possible.

106. The model is obviously stylized, but there are good reasons why land should serve better as collateral than capital goods - capital goods tend to be constructed for specific purposes, and are less malleable, less alterable to other uses, with often large asymmetries of information concerning the prospects of returns not only in the intended use, but also in alternative uses. There are other reasons that the provision of credit typically gets reflected in land bubbles (or bubbles in other fixed assets): when the price of capital goods exceeds the production costs, the supply will increase, and this limits the extent to which the price can rise or the duration of any bubble associated with a produced good. (Nonetheless, bubbles of produced goods do occur - the tech bubble in the nineties and the tulip bubble in the seventeenth century being the most famous instances.)

The model can easily be generalized. We have assumed, in particular, that capitalists-entrepreneurs are the only ones who do real savings, while landowners/rentiers simply buy land, and that credit is only provided to the latter rather than the former. In the final subsection, we allow credit against capital goods as collateral.

107. For simplicity, here we assume that $s_{p}$ is the gross savings rate, which is assumed to be fixed and based on gross income, where $r$ is now the gross return to capital. We could rewrite all of these equations based on net savings and net income, without changing any of the results.

108. Because we do not want to address issues involving the banking system and the wealth of its owners, we will simplify the analysis and assume that it is government owned. As formulated, the banking system makes neither profits nor losses.

109. In Part I of this paper, we noted that this characterized several countries.

110. This analysis, however, does not explain why workers' compensation should have decreased even as average productivity has increased. Of course, average productivity could have increased even if the ratio of capital per effective labor unit decreased, simply because of technological change.

111. In the analysis below, we assume that the rate charged is zero. This is a simplifying assumption. All that is required is that the rate charged by less than $\mathrm{F}_{\mathrm{K}}$.

112. This assumes, of course, that the change in policy was not anticipated.

113. This can be seen most transparently in a situation where the economy is initially at full employment. Assume that savings (consumption) is interest insensitive If financial regulations were eased, so that banks could lend more, given their deposits and net worth (reserve and capital adequacy requirements were loosened), it would appear that banks could lend more, and if banking is profitable at the margin, each bank would believe such a policy would be desirable. But if they all 
started to lend more, there would be excess demand, and the Fed would have to raise interest rates, to tighten credit in a fully offsetting way.

114. We again assume a constant labor supply and normalize the labor supply at unity.

115. With all of profits going into (gross) investment, aggregate consumption must equal wages. Second petiod consumption is just $B+r_{g} B$, that is, $C_{1}+C_{2}=(1-s)$ $(w-\tau)+\tau+B=w-s(w-\tau)+B=w$, from which the result follows immediately.

116. Recall that capitalists' savings behavior determines $\mathrm{r}: \mathrm{s}_{\mathrm{p}} \mathrm{r}=\mathrm{n}$. In the remainder of this section, we assume $s_{p}=1$.

117. $\tau=r^{*} B=s r_{g} w /\left(1+s r_{g}\right) \cdot \frac{d \log \tau}{d \log r_{g}}=1-\frac{s r_{g}}{1+s r_{g}}=\frac{1}{1+s r_{g}}>0$.

118. $C_{2}=\left(1+r_{g}\right) B=\left(1+r_{g}\right) \frac{s w}{1+s r_{g}} \cdot \frac{d \log C_{2}}{d \log r_{g}}=\frac{r_{g}}{1+r_{g}}-\frac{s r_{g}}{1+s r_{g}}=\frac{r_{g}\left(1+s r_{g}-s-s r_{g}\right)}{\left(1+r_{g}\right)\left(1+s r_{g}\right)}=\frac{r_{g}(1-s)}{\left(1+r_{g}\right)\left(1+s r_{g}\right)}>0$.

119. Steady-state utility of workers is maximized at $U\left(C_{1}, w-C_{1}\right)$, i.e. where $U_{1}=U_{2}$ Individuals will choose this allocation if $r=0$. One could conduct a full dynamic analysis, rather than focusing on steady states, with much the same results. Focusing on steady states greatly simplifies the calculations.

120. If we had expanded the model to include land (as in earlier sections), there will also be an increase in its value.

121. In our model, the rate of growth of the labor force is zero, and the rate of labor augmenting technical progress is zero. Thus, the long run rate of growth of the economy is zero. The critical condition involves the relationship between the rate of interest and the rate of growth.

Standard focuses on the zero lower bound constraint. This is a lower bound on the nominal interest rate. In the United States, in the aftermath of the crisis, the real interest rate has been negative.

122. $\frac{d \log (s w / K)}{d \log \left(r_{s}\right)}=\left(\frac{-K^{2} F_{K K}}{f-K F_{K}}-1\right) \frac{d \log (K)}{d \log \left(r_{z}\right)}=\left(\frac{S_{K}}{\varepsilon}-1\right) \frac{d \log (K)}{d \log \left(r_{s}\right)}$ where $\varepsilon$ is the elastictty of substitution and $S_{X}$ is the share of capital. We note that because we have normalized labor supply at unity, which is fixed, the capital--labor ratio, usually denoted by $\mathrm{k}$, is the same as the level of capital stock, $K$ (The elasticity of substitution is equal to $\left.F_{K}\left(F-K F_{K}\right) / K F_{K K} F\right)$

123. For a discussion of the merits of income contingent loans, see Chapman et al 2014

124. We note that we are able to derive a simple formula describing tail inequality. In the case of a Solow model (all save the same fraction $s$ of their income) with all receiving the same wage but stochastic returns to capital, the Pareto coefficient is given by $2 s^{2} \frac{1-S_{k}}{S_{k}^{2} n \bar{\sigma}^{2}}$, where $\bar{\sigma}^{2}$ is the variance of returns. In the limiting case where variance is zero, we obtain the earlier result of Stiglitz (1969) that there is no inequality. Note again that the difference between $\mathrm{r}$ and growth plays no role, but the share of capital does.

125. We show that increases in credit available (decreases in collateral requirements) can give rise to increases in land values, but we have also shown that there can be land bubbles even in the absence of credit expansion (though recent bubbles have clearly been supported by such credit expansion.)

126. See, for example, Piketty (2014) and Stiglitz (2012b). Such changes affect both the distribution of income and wealth at any moment of time as well as the dynamics that describe the evolution of those variables. This paper has taken technology as exogenous, but as Braverman and Stiglitz (1989) point out, technology and technological change itself is affected by societal inequalities. Sharecropping is a prevalent 
tenancy arrangements in economies with large disparities in land ownership, but not otherwise. But the choice of technology at one moment affects the distribution of income and wealth and wealth dynamics, and even the nature of technological change (Greenwald and Stiglitz, 2014).

127. The points raised here (and similar points made elsewhere in this paper) are echoed in Suresh Naidu's excellent review of Piketty (2014).

128. The result follows immediately upon observing that we can write $\bar{w}(K)=\left(F_{\ell_{1}} \omega+\right.$ $F_{L_{2}}(1-\omega)$ ), and treating $\mathrm{K}$ and $\omega$ as functions of time.

129. Now $\frac{k^{w *}}{k^{*}}=\frac{n s\left(\frac{1-S_{k}}{S_{k}}+\tau^{c}\right)}{s_{p}\left(1-\tau^{c}\right)+s\left(k^{*}\right) \tau^{c} n}$. So long as $s_{p}>n s$, the direct effect of an increase in taxes is to increase the importance of life cycle savings. If the elasticity of substitution is greater than one, the indirect effect is aiso positive, so long as $s^{\prime} \leq 0$. (Now the workers' savings rate plausibly depends on $\mathrm{k}$, since there is no taxation on the return to life cycle savings, and the before tax return increases.)

130. We can in principle derive the savings functions from $\mathrm{V}$.

131. We have made use of the fact that for an indirect utility function, $\frac{\partial V}{\partial r}=s\left(k^{\star}\right)$ $w\left(k^{*}\right) \frac{\partial V}{\partial Y^{W}}$.

132. This analysis assumes that social welfare is only assessed from the perspective of workers (who receive no inheritances.) It ignores the welfare of the capitalists. If their wellbeing were also included within the social welfare function, the optimal tax would obviously be different. Note the steady state income of the capitalists always decreases with taxation, that is, $\frac{d}{d \tau^{c}}\left(\left(1-\tau^{c}\right) r k^{*}\right)=\left(1-\tau^{c}\right)\left(f^{\prime}\left(k^{*}\right)+f^{\prime \prime}\left(k^{*}\right) k^{*}\right)$ $\frac{d k^{*}}{d \tau^{c}}-r\left(k^{*}\right) k^{*}=\frac{f^{\prime}(k) f^{\prime}(k)}{f^{n}(k)}<0$, but so does income per capita.

\section{References}

Acemoglu, Daron, D. Autor, D. Dorn, G. Hanson, and B. Price (2014) "Import Competition and the Great U.S. Employment Saga of the 2000s," NBER Working Paper.

Aitchison, John and J.A.C Brown (1957) "The Lognormal Distribution," The Economic Joumal, vol. 67, no. 268, pp. 713-15.

Arnott, R. and J.E. Stiglitz (1979) "Aggregate Land Rents, Expenditure on Public Goods and Optimal City Size," Quarterly Journal of Economics, vol. 93, no. 4, pp. 471-500.

Arrow, Kenneth J., Hollis B. Chenery, Bagicha S. Minhas, and Robert M. Solow (1961) "Capital-Labor Substitution and Economic Efficiency," The Review of Economics and Statistics, vol. 43 , no. 3 , pp. $225-50$.

Atkinson, A.B. and J.E. Stiglitz (1976) "The Design of Tax Structure: Direct Versus Indirect Taxation," Journal of Public Economics, vol. 6 (July-August), pp. 55-75.

Autor, David (2002) "Skill Biased Technical Change and Rising Inequality: What is the Evidence? What are the Alternatives?" Working paper, MIT and NBER.

Autor, D.H., L.F. Katz, and M.S. Kearney (2008) "Trends in US Wage Inequality: Revising the Revisionists," Review of Economics and Statistics, vol. XC, no. 2, pp. 300-23.

Banerjee, Abhijit and Sendhil Mullainathan (2010) "The Shape of Temptation: Implications for the Economic Lives of the Poor," NBER Working Paper 15973. 
Becker, Gary S. and Nigel Tomes (1979) "An Equilibrium Theory of the Distribution of Income and Intergenerational Mobility," Journal of Political Economy, vol. 87, no. 6, pp. $1153-89$.

Becker, Gary S. and Nigel Tomes (1986) "Human Capital and the Rise and Fall of Families," Joumal of Labor Economics, vol. 4, no. 3, pp. S1-\$39.

Becker, Gary S. and Nigel Tomes (1994) "Human Capital and the Rise and Fall of Families," in Gary S. Becker (ed.), Human Capital: A Theoretical and Empirical Analysis with Special Reference to Education, 3rd edition. Chicago: The University of Chicago Press.

Bernanke, Ben S. (2005) "The Global Saving Glut and the US Current Account Deficit," The Sandridge Lecture, Virginia Association of Economists, Richmond, VA.

Bevan, D. and J.E. Stiglitz (1979) "Intergenerational Transfers and Inequality," The Greek Economic Review, no. 1, pp. 8-26.

Bowles, Samuel and Herbert Gintis (2002) "The Inheritance of Inequality,." Journal of Economic Perspectives, vol. 16, no. 3, pp. 3-30.

Braverman, A. and J.E. Stiglitz (1989) "Credit Rationing, Tenancy, Productivity and the Dynamics of Inequality," in P. Bardhan (ed.), The Economic Theory of Agrarian Institutions Oxford: Clarendon Press, pp. 185-201.

Card, David and John E. DiNardo (2002) "Skill-Biased Technological Change and Rising Wage Inequality: Some Problems and Puzzles," Journal of Labor Economics, vol. 20, no. 4 , pp. $733-83$.

Carroll, Christopher D. (1998) "Why Do the Rich Save So Much?," NBER Working Papers 6549.

Champernowne, D.G. (1953) "A Model of Income Distribution," Economic Journal, vol. LXIIII, pp. 318-51.

Chapman, B., T. Higgins, and J. E. Stiglitz (eds) (2014). Income Contingent Loans: Theory, Practice and Prospects. Basingstoke, UK and New York: Palgrave Macmillan.

Dasgupta Partha and Joseph Stiglitz (1980) "Industrial Structure and the Nature of Innovative Activity," The Economic Journal, vol, 90, no. 358, pp. 266-93.

Domar, Evsey D., and Richard A. Musgrave (1944) "Proportional Income Taxation and Risk-taking," Ouarterly Joumal of Economics, vol. 58 , no. 3, pp. 388-422.

Dynan, Karen, Jonathan Skinner, and Stephen P. Zeldes (2004) "Do the Rich Save More?," Journal of Political Economy, vol. 112, no. 2, pp. 397-444

Federal Reserve Board (2015) The State of Lending in America \& Its Impact on U.S. Households: The Cumulative Costs of Predatory Practices.

Feldstein, Martin (2014) "Piketty's Numbers Don't Add Up," Wall Street Joumal, May 14. Available at http://online.wsj.com/articles/SB100014240527023040818045795576641 76917086.

Galbraith, James Kenneth (2012) Inequality and Instability: A Study of the World Economy Just Before the Great Crisis. Oxfotrd: Oxford University Press.

George Henry (1879) Progress and Poverty: An Inquiry into the Cause of Industrial Depressions and of Increase of Want with Increase of Wealth VI. New York: Robert Schalkenbach Foundation.

Giovannoni, Olivier G. (2014) "What Do We Know About the Labor Share and the Profit Share? - Part III: Measures and Structural Factors," Bard College, March 3.

Giovannoni, Olivier G. (2015) "Inequality: Challenge of the Century?," Presentation to the ASSA meetings, Boston, January 3.

Griliches, Zvi (1969) "Capital-Skill Complementarity," The Review of Economics and Statistics, vol. 51, no. 4, pp. 465-8.

Greenwald, Bruce and Judd Kahn (2009) Globalization: $n$. the Irrational Fear That Someone in China Will Take Your Yob. Hoboken, NJ: John Wiley \& Sons. 
Guzman, M. and J.E. Stigilitz (2014) "Pseudo-wealth and Consumption Fluctuations," Columbia University.

Hahn F. (1966) "Equilibrium Dynamics with Heterogeneous Capital Goods," Quarterly Journal of Economics, vol. 80, pp. 633-46.

Henry, C. and J.E. Stiglitz (2010) "Intellecutal Property, Dissemination of Innovation, and Sustainable Development," Global Policy, vol. 1, no. 1, October, pp: 237-51.

Hotelling, Harold (1931) "The Economics of Exhaustible Resources," Journal of Political Economy, April.

Jones, C., and Paul Romer (2009) "The New Kaldor Facts: Ideas, Institutions, Population, and Human Capital," NBER Working Paper 15094, June.

Kaldor, Nicholas (1957) "A Model of Economic Growth," The Economic Yournal, vol. 67, no. 268, pp. 591-624.

Kaldor, Nicholas (1961) "Capital Accumulation and Economic Growth," in F.A. Lutz and D.C. Hague (eds), The Theory of Capital. St. Martins Press, pp. 177-222.

Katz, Michael L. and Carl Shapiro (1994) "Systems Competition and Network Effects," Journal of Economic Perspectives, vol. 8, no. 2, pp. 93-115.

Kindleberger, Charles P. and Robert Aliber (1978) Manias, Panics, and Crashes: A History of Financial Crisis. New York: John Wiley \& Sons.

Knolly, Katharina, Moritz Schularickz, and Thomas Steger (2014) "Home Prices Since 1870: No Price Like Home," Vox, November 1.

Knolly, Katharina, Moritz Schularickz, and Thomas Steger (2015) "No Price Like Home: Global House Prices, 1870-2012," working paper.

Krusell, Per, Lee E. Ohanian, Jose-Victor Rios-Rull, and Giovanni L. Violante (2000) "Capital-Skill Complementarity and Inequality: A Macroeconomic Analysis," Econometrica, vol. 68, no. 5, pp. 1029-54.

Kuznets, Simon (1955) "Economic Growth and Income Inequality," The American Economic Review, vol. 45, no. 1, pp. 1-28.

Lebergott, Stanley (1959) "The Shape of the Income Distribution," The American Economic Review, vol, 49 , no. 3, pp. 328-47.

Mallick, Debdulal (2007) "The Role of the Elasticity of Substitution in Economic Growth: A Cross-Country Test of the de La Grandville Hypothesis," Economic series, Deakin University, Faculty of Business and Law, School of Accounting, Economics and Finance.

Mason, Joshua W. (2014) "Three Essays in Macroeconomic History", University of Massachusetts Amherst.

Mason, Joshua W. (2015) "Disgorge the Cash," Working Paper, Roosevelt Institute.

Milevsky, Moshe A, and Huaxiong Huang (2011) "Spending Retirement on Planet Vulcan: The Impact of Longevity Risk Aversion on Optimal Withdrawal Rates," Financial Analysts Journal, vol. 67, no. 2, pp. 45-58.

Naidu, Suresh (2014). "Capital Eats the World." https://www.jacobinmag.com/2014/05/ capital-eats-the-world/.

OECD (2011) Divided We Stand: Why Inequality Keeps Rising. Paris: OECD.

OECD (2013) Pension Markets in Focus. Paris: OECD.

Pasinetti, L. (1962) "The Rate of Profit and Income Distribution in Relation to the Rate of Economic Growth," Review of Economic Studies, vol. 29, no. 4, pp. 267-79.

Piketty, Thomas (2014) Capital in the Twenty-First Century. Cambridge, MA: The Belknap Press of Harvard University Press.

Piketty, Thomas and Gabriel Zucman (2014) "Capital is Back: Wealth-Income Ratios in Rich Countries 1700-2010," Quarterly Journal of Economics, vol. 129, no. 3, pp. 1155-210. Piketty, Thomas and Emmanuel Saez (2003) "Income Inequality in the United States, 1913-1998," Quarterly Journal of Economics, vol. 118, no. 1, pp. 1-39. (Longer updated 
version published in A.B. Atkinson and T. Piketty eds, Oxford University Press, 2007.) (Tables and figures updated to 2012 in Excel format, September 2013.)

Piketty, Thomas, Emmanuel Saez, and Stefanie Stantcheva (2014) "Optimal Taxation of Top Labor Incomes: A Tale of Three Elasticities," American Economic Joumal: Economic Policy, vol. 6, no. 1, pp. 230-71.

Pogge, Thomas and Saniay Reddy (2010) "How Not to Count the Poor;" in Joseph Stiglitz, Sudhir Anand and Paul Segal (eds), Debates in the Measurement of Poverty. Oxford: Oxford University Press.

Roberts, Sam (2014) "Why are Rockefellers Moving from 30 Rock? 'We Got a Great Deal'," New York Times, November 24, p. A1.

Saez, Emmanuel and Gabriel Zucman (2014) "Wealth Inequality in the Unites States Since 1913: Evidence from Capitalized Income Tax Data," NBER Working Paper 20625.

Scheinkman, J.A., and W. Xiong (2003) "Overconfidence and Speculative Bubbles," Journal of Political Economy, vol. 111, no. 6, pp. 1183-219.

Shell, Karl, and Joseph E. Stiglitz (1967) "Allocation of Investment in a Dynamic Economy," Quarterly Joumal of Economics, vol. 81, pp. 592-609.

Shell, K., M. Sidrauski, and J.E. Stiglitz (1969) "Capital Gains, Income and Savings," Review of Economic Studies, vol. 36, no. 1, pp. 15-26.

Shierholz, Heidi and Lawrence Mishel (2013) "A Decade of Flat Wages," Economic Policy Insitute Report, available at http://www.epi,org/publication/a-decade-of-flat-wagesthe-key-barrier-to-shared-prosperity-and-a-rising-middle-class/.

Shierholz, Heidi, Lawrence Mishel, and John Schmitt (2013) "Don't Blame the Robots: Assessing the Job Polarization Explanation of Growing Wage Inequality," Economic Policy Institute, November 19.

Sraffa, Piero (1960) Production of Commodities by Means of Commodities: Prelude to a Critique of Economic Theory. London: Cambridge University Press.

Stiglitz, Joseph E. (1966) "The Distribution of Income and Wealth Among Individuals," Presented at the December 1966 meetings of the Econometric Society, San Francisco, December 29 (MIT, mimeo).

Stiglitz, Joseph E. (1969a) "Distribution of Income and Wealth Among Individuals," Econometrica, vol. 37, no. 3, pp. 382-97.

Stiglitz, Joseph E. (1969b) "The Effects of Income, Wealth and Capital Gains Taxation on Risk-Taking." Quarterly Joumal of Economics, vol. 83, no. 2, pp. 263-83.

Stiglitz, Joseph E. (1974) "The Cambridge-Cambridge Controversy in the Theory of Capital: a view from New Haven: a Review Article," Journal of Political Economy, vol. 82, no. 4, pp. 893-903.

Stiglitz, Joseph E. (1975) "The Theory of Screening, Education and the Distribution of Income," American Economic Review, vol. 65, no. 3, June, pp. 283-300. Reprinted in Selected Works of Joseph E. Stiglitz, Volume I; Information and Economic Analysis. Oxford: Oxford University Press, 2009, pp. 99-121.

Stiglitz, Joseph E. (2003) The Roaring Nineties: A New History of the World's Most Prosperous Decade. New York: W.W. Norton \& Company.

Stiglitz, Joseph E. (2010a) Freefall: America, Free Markets, and the Sinking of the World Economy. New York: WW Norton.

Stiglitz, Joseph E. (2010b) "The Wobbly Economy," mimeo, Columbia University.

Stiglitz, Joseph E. (2012a) The Price of Inequality: How Today's Divided Society Endangers Our Future. New York: W.W. Norton. Also published in the UK by Penguin/Allen Lane Translated in simplified Chinese by China.

Stiglitz, Joseph E. (2012b) "Macroeconomic Fluctuations, Inequality, and Human Development," Joumal of Human Development and Capabilities, vol, 13, no. 1, pp. 31-58. 
Reprinted in Deepak Nayyar (ed.), Macroeconomics and Human Development. London: Taylor and Francis.

Stiglitz, Joseph E. (2013) "Stable Growth in an Era of Crises: Learning from Economic Theory and History," Ekonomi-tek, vol. 2, no. 1, pp. 1-38. (Originally delivered as keynote lecture to the Turkish Economic Association. Izmir, November, 2012.)

Stiglitz, Joseph E. (2014a) "Unemployment and Innovation," NBER Working Paper 20670.

Stiglitz, Joseph E. (2014b) "Inequality in America: A Policy Agenda for a Stronger Future: 2014, Daniel Patrick Moynihan Lecture on Social Science and Public Policy," Annals of the American Academy of Political and Social Scieinces.

Stiglitz, Joseph E. (2014c) "Tapping the Brakes: Are Less Active Markets Safer and Better for the Economy?" Presented at the Federal Reserve Bank of Atlanta 2014 Financial Markets Conference Tuning Financial Regulation for Stability and Efficiency, April 15. Available at http://www.frbatlanta.org/documents/news/conferences/14fmc/ Stiglitz.pdf.

Stiglitz, Joseph E. (2015a) "Fed Policy, Inequality, and Equality of Opportunity," keynote address to The Ninth Biennial Federal Reserve System Community Development Research Conference, April 3.

Stiglitz, Joseph E. (2015b) "New Theoretical Perspectives on the Distribution of Income and Wealth among Individuals," Roosevelt Institute Working Paper.

Stiglitz, Joseph E. (2015c) "Devolution, Independence, and the Optimal Provision of Public Goods," Economics of Transportation, vol. 4, no. 1, pp. 82-94.

Stiglitz, Joseph E. (2015d) "In Praise of Frank Ramsey's Contribution to the Theory of Taxation," Economic Journal.

Stiglitz, Joseph E. and Bruce. C. Greenwald (2014) Creating a Learning Society: A New Approach to Growth, Development, and Social Progress. New York: Columbia University Press.

Stiglitz, Joseph E. and Andrew Weiss (1981) "Credit Rationing in Markets with Imperfect Information," American Economic Review, vol. 71, no. 3, pp. 393-410.

Stiglitz, Joseph E., A. Sen, and J-P Fitoussi (2010) Mismeasuring Our Lives: Why GDP Doesn't Add Up. New York: The New Press.

United Nations (2012) World Population Prospects: The 2012 Revision.

Wolff, Edward N. and Maury Gittleman (2011) "Inheritances and the Distribution of Wealth Or Whatever Happened to the Great Inheritance Boom?," BLS Working Paper 445 , January.

Young, Andrew T. (2013) "US Elasticity of Substitution and Factor-Augmentation at the Industry Level," Macroeconomic Dynamics, vol. 17, no. 4, pp. 861-97, 